NBER WORKING PAPER SERIES

\title{
ENDOGENOUS SKILL BIAS IN TECHNOLOGY ADOPTION: CITY-LEVEL EVIDENCE FROM THE IT REVOLUTION
}

\author{
Paul Beaudry \\ Mark Doms \\ Ethan Lewis \\ Working Paper 12521 \\ http://www.nber.org/papers/w12521
NATIONAL BUREAU OF ECONOMIC RESEARCH
1050 Massachusetts Avenue
Cambridge, MA 02138
September 2006

The authors would like to thank Daron Acemoglu, David Autor, Elizabeth Cascio, David Green, Larry Katz, Thomas Lemieux, and seminar participants at UBC, LSE, UCL, the NBER Summer Institute, and the New York Federal Reserve for very helpful discussions and to Meryl Motika for research assistance. The views expressed herein are those of the author(s) and do not necessarily reflect the views of the National Bureau of Economic Research.

(C2006 by Paul Beaudry, Mark Doms and Ethan Lewis. All rights reserved. Short sections of text, not to exceed two paragraphs, may be quoted without explicit permission provided that full credit, including (C) notice, is given to the source. 
Endogenous Skill Bias in Technology Adoption: City-Level Evidence from the IT Revolution Paul Beaudry, Mark Doms and Ethan Lewis

NBER Working Paper No. 12521

September 2006

JEL No. E13, J31, O33

\begin{abstract}
$\underline{\text { ABSTRACT }}$
This paper focuses on the bi-directional interaction between technology adoption and labor market conditions. We examine cross-city differences in PC-adoption, relative wages, and changes in relative wages over the period 1980-2000 to evaluate whether the patterns conform to the predictions of a neoclassical model of endogenous technology adoption. Our approach melds the literature on the effect of the relative supply of skilled labor on technology adoption to the often distinct literature on how technological change influences the relative demand for skilled labor. Our results support the idea that differences in technology use across cities and its effects on wages reflect an equilibrium response to local factor supply conditions. The model and data suggest that cities initially endowed with relatively abundant and cheap skilled labor adopted PCs more aggressively than cities with relatively expensive skilled labor, causing returns to skill to increase most in cities that adopted PCs most intensively. Our findings indicate that neo-classical models of endogenous technology adoption can be very useful for understanding where technological change arises and how it affects markets.
\end{abstract}

\author{
Paul Beaudry \\ Department of Economics \\ University of British Columbia \\ Room 997-1873 East Mall \\ Vancouver, B.C. Canada V6T 1Z1 \\ and NBER \\ paulbe@interchange.ubc.ca \\ Mark Doms \\ Federal Reserve Bank of San Francisco \\ 101 Market Street, Mail Stop 1130 \\ San Francisco, CA 94105 \\ mark.doms@sf.frb.org \\ Ethan G. Lewis \\ Economics Department \\ Dartmouth College \\ Hanover, NH 03755 \\ ethan.g.lewis@dartmouth.edu
}




\section{Introduction}

Research examining the relationships between technology and skilled labor usually takes one of two forms. The first, addressed in a voluminous literature on skill-biased technological change, examines to what extent relative demand for skilled labor may be influenced by technology. ${ }^{1}$ The second examines to what extent technology adoption is affected by the relative supply of skilled labor. ${ }^{2}$ More rarely are both forms approached simultaneously, though the existence of such rich literatures in both areas argues that accurately identifying either the effects of technology on the demand for skilled workers, or the effects of skill supply on technology adoption, will be difficult.

In this paper we address this difficulty by first presenting a neoclassical model of endogenous technological adoption - similar in spirit to some used in the economic history literature that has implications regarding the supply of skill, the returns to skill, technology adoption, and changes in the return to skill. To test the predictions of the model, we use a dataset on technology, skills, and returns to skill for a sample of 230 U.S. cities over the main period of diffusion of the personal computer (PC), that is, from 1980 to 2000. In addition to having appropriate skill and technology measures, identification requires the use of valid instruments of skill across cities, and we use those developed in Doms and Lewis (2006). Indeed we find that the predictions of the model closely align with the patterns observed in our cross-city data.

The model examines how the supply of skilled labor affects the adoption of new technology, and then how that adoption subsequently affects the demand for labor. The structure of the model stems from the observation that firms often face many choices in the mix of techniques used to produce a good, and the choice of techniques is influenced by the factor prices facing the firm. ${ }^{3}$ As such, the model implies that new technologies are initially attractive only for localities facing particular configurations of factor prices; it may be optimal for one locality to adopt a new technology-if it has a comparative advantage in doing so-while in a different locality it is optimal to maintain an old technology. In the case of the PC (a proxy for information technology more generally), cities that have a relative abundance of skilled labor (a factor complementary to PCs) tend to have low relative wages of skilled workers

\footnotetext{
${ }^{1}$ For recent examples see Author, Levy, and Murnane (2003), Autor, Katz, and Kearney (2006).

${ }^{2}$ For example, see Comin and Hobijn (2004) and Benhabib and Speigel (2005).

${ }^{3} \mathrm{An}$ attractive feature of the choice of technique model is that relatively few parameters allows for a very rich set of substitution possibilities between inputs.
} 
and therefore also adopt PCs more aggressively. ${ }^{4}$

The model predicts that as the price of the new technology declines over time, the conditions for profitable adoptions increase, supporting a dynamic process with diffusion progressing both on the intensive (within localities) and the extensive margin (across localities). Further, the model predicts that those cities that adopt PCs most aggressively are the cities where relative wages will rise the most. However, in the absence of externalities, the rise in relative wages as a result of $\mathrm{PC}$ adoption will not be so great so as to create a positive association between the supply of skill and the return to skill. Finally, the model predicts that real wages of skilled workers will increase as technology is adopted whereas the wages of unskilled workers will remain flat or even fall.

Consistent with the model, we find that it is in cities where high school educated workers are more costly (and scare) relative to college educated workers that PCs were adopted most intensely. It is also these cities that experience the greatest increase in the returns to education. That is, it is cities that possess a more abundant supply of college educated workers that adopted PCs most intensively and saw the returns to college increase fastest; the downward slope across cities between the supply of skill and the return to skill that existed from 1970 to 1990 dissipates by 2000. As the model suggests, the high PC adopting cities are not observed to have higher returns to education in 2000 than their slower adopting counterparts. Notice that this observation contrasts with common intuition regarding the likely correlation between PC use and returns to education, but it is consistent with the endogenous technology adoption framework. ${ }^{5}$

The economic history literature has employed models similar to ours. For example, Habakkuk (1962) argues that land abundance in the United states affected relative factor prices and thereby lead to different patterns of technological adoption compared to England. Another example, Goldin and Sokoloff (1984), posit that factor prices differences in 1830 between the northern and southern U.S. states (due to crop differences) help explain the differential patterns of industrialization. Similarly to the model that we present and test, Goldin and

\footnotetext{
${ }^{4}$ Our approach stands in contrast to many other models that rely on other mechanisms to explain patterns of technology diffusion. Doms and Lewis (2006) examine a variety of factors related to technology diffusion and find that the most important factor in understanding the large variance in PC use across cities is the supply of human capital. The present paper extends Doms and Lewis (2006) by specifying and testing the mechanism that drives these differences in PC adoption.

${ }^{5} \mathrm{An}$ important byproduct of our analysis is the observation that city-level wages do not behave as if there where fully integrated into an national aggregate. Instead we find that city level wages are determined locally in conjunction with $\mathrm{PC}$ use.
} 
Sokoloff (1984) find that areas with relatively low payments to factors complementary to a new technology are the areas that adopt the technology (industrialization in their case) was adopted most aggressively. Further, like our model and results, payments to those factors rise fastest in areas where technology was adopted most aggressively. ${ }^{6}$

This paper is also closely related to the recent literature on endogenous bias in technology which emphasizes two avenues by which factor supplies can affect the bias of technological change. First, market conditions may influence the direction of research and thereby favor innovations that are biased towards or against a particular factor. This avenue reflects the endogeneity of technology supply (see for example Acemoglu 1998, 2002). Alternatively, market forces may affect decisions regarding which technologies to adopt. In contrast with the innovation route, this second avenue reflects the potential endogeneity of the demand for biased technologies (see for example Atkinson and Stiglitz (1969), Basu and Weil (1998), Caselli (1999), Beaudry and Green (1998, 2003, and 2005), Caselli and Coleman (2006)). Our exploration focuses on the relevance of this second channel. ${ }^{7}$

The remaining sections of the paper are structured as follows. In section 2, we present a simple model of biased technology adoption and derive a set of implications regarding local level interactions between returns to education, changes in returns to education, and technology use. In our model, the labor market is viewed as a local market while the market for technologies is a global market. Further, firms have a choice between a more and less skilled biased technology where the skilled biased technology is PC-intensive. In Section 3 we discuss the data. In Section 4 we explore a set of empirical patterns predicted by the theory. Section 5 examines and dispels several alternative explanations for our results. This section also shows how our choice of technique model differs from other, more commonly used models of production, and how those other models fail to capture all of the observed phenomena that we document. Section 6 offers concluding comments.

\footnotetext{
${ }^{6}$ Another example in this neoclassical literature is Manuelli and Seshadri (2004) that examine the diffusion of the farm tractors across the US in the early 20th century. For an analysis of a more recent time period, Beaudry and Green (2003) argues that differences in factor accumulation between the US and Germany may have caused differences in technological choices and thereby differences in wages and employment patterns.

${ }^{7}$ Although our paper focuses on the second channel, the first channel provides at least a partial explanation as to why PCs may have been developed to be complements with skilled labor, where skilled labor has increased in abundance.
} 


\section{A neoclassical model of technology adoption}

Consider a environment where firms have access to a set of technologies to produce a final good denoted by $Y_{t}$. The production of $Y_{t}$ requires inputs $X_{t}$, where these inputs can be organized in different ways to produce output, each of these alternative organizations corresponding to a different technology. If we parameterize the different technologies by $\theta \in \Theta$, then the production possibilities facing a firm can be represented by:

$$
F\left(X_{t}, \theta\right), \quad \theta \in \Theta_{t}
$$

where for each $\theta \in \Theta$, the production function is assumed to satisfy constant returns to scale and concavity. In this case, a price taking firm will aim to maximize profits by solving the following problem,

$$
\max _{X_{t}, \theta_{t}} F\left(X_{t}, \theta_{t}\right)-w_{t} X_{t}
$$

where $w_{t}$ is the vector of factor prices. In such an environment, it is straightforward to extend the definition of a competitive equilibrium to include the choice of technologies, that is, a competitive equilibrium can be defined as a set of prices, allocations and technology choices, such that given prices, allocations and technology choices are optimal, and markets clear. ${ }^{8}$

Let us now consider the situation with a set of distinct markets, indexed by $i$. Each of these markets is assumed to have access to the same set of technologies, but differ in terms of the supply of at least a subset of the factors $X$. The question we want to ask, is how do the different markets react to a a change in the set of choices, that is, a change in $\Theta_{t}$. Obviously, the answer to this question depends on the nature of the change in $\Theta$. In particular, given the time period that interests us, we want to examine the effects of having $\Theta$ extend to include a more skilled biased technology relative to the pre-existing choices. To this end, we will focus on the case where initially there is only one dominant technology used across all markets. This technology uses as inputs skilled labor $S$, unskilled labor $U$ and traditional capital $K$. The market for skilled and unskilled labor is assumed to be a local market, with exogenously fixed local supplies. The market for $K$ is assumed to be a common market, where firms from all localities can rent the capital at the rate $r^{k}$. Finally, for ease of presentation, the pre-existing technology is assumed to have the following functional form:

\footnotetext{
${ }^{8}$ Standard techniques can be used to prove the existence of a competitive equilibrium with technology choices
} 


$$
F^{T}(K, S, U)=K^{1-\alpha}\left[a S^{\sigma}+(1-a) U^{\sigma}\right]^{\frac{\alpha}{\sigma}}, \quad 0<\alpha<1, \quad 1<a<1, \quad-\infty<\sigma<1
$$

In this environment, the initial returns to skill will differ across markets. In particular, the ratio of the market specific skilled wage $w_{i}^{S}$ to the unskilled wage $w_{i}^{U}$ will be given by:

$$
\frac{w_{i}^{S}}{w_{i}^{U}}=\frac{a S_{i}^{\sigma-1}}{(1-a) U_{i}^{\sigma-1}}
$$

where $S_{i}$ and $U_{i}$ represent the quantities of skilled labor available market i.

Now suppose that at a point in time, say at $t=0$, a new technology becomes available. This technology has two characteristics that differentiate it from the traditional technology. First, it uses a different form of capital, which we will denote as $P C$ capital. This $P C$ capital is assumed to be available on a common market at rental rate $r^{P C}$. Second, the new technology is assumed to be skilled biased relative to the old technology in the sense that a common factor prices, the new technology uses skilled labor more intensively (i.e., has a higher ratio of $\frac{S}{U}$ ). These features are captured in the following functional form for the new technology:

$$
F^{N}(P C, S, U)=P C^{1-\alpha}\left[b S^{\sigma}+(1-b) U^{\sigma}\right]^{\frac{\alpha}{\sigma}}, \quad a<b<1
$$

What is important to notice is that the new technology does not dominate the old technology in the sense of producing more output at any input combinations. In effect, for given rental rates of capital $r^{K}$ and $r^{P C}$, the old technology is more productive than the new technology when used with a small fraction of skilled workers, while the new technology is more productive (higher output per worker) when used with a high fraction of skilled workers. This property is depicted in Figure 1. 
Figure 1: Effects of Technological Choice

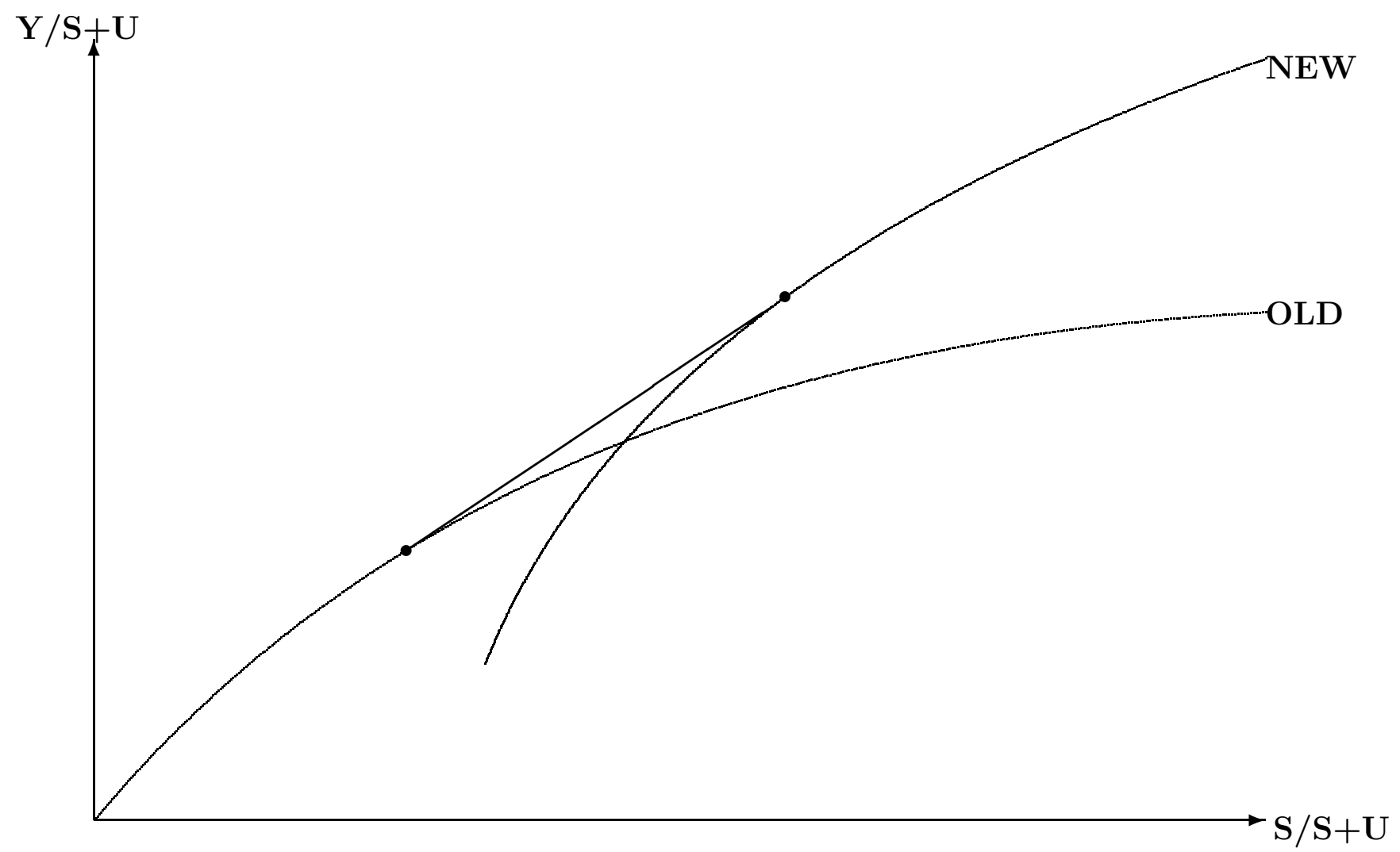

From Figure 1, it is easy to infer that localities with high ratios of skilled to unskilled workers will want to adopt the new technology, while those with low levels of skill may want to maintain the old technology. Actually, in such a situation, the adoption decision is characterized by three regions delimited by critical values of skill to unskilled ratios. In particular, it is easy to verify that there exist $\phi^{L}$ and $\phi^{H}\left(0<\phi^{L}<\phi^{H}\right)$ such that if a locality is characterized $\frac{S_{i}}{S_{i}+U_{i}}<\phi^{L}$, then it maintains the old technology. If $\frac{S_{i}}{S_{i}+U_{i}}>\phi^{H}>\phi^{L}$, then the locality switches completely to the new technology. Finally if $\phi^{L}<\frac{S_{i}}{S_{i}+U_{i}}<\phi^{H}$ then both technologies co-exist in a competitive equilibrium, with the fraction of production done using the new technology being an increasing function of $\frac{S_{i}}{S_{i}+U_{i}} \cdot{ }^{9}$ Since $P C$ capital is used intensively in the new technology, it follows that the quantity of PCs per worker used in a locality is a monotonically increasing function of the ratio of skilled to unskilled workers. ${ }^{10}$

${ }^{9}$ The values of $\phi^{L}$ and $\phi^{H}$ are defined by

$$
\left(\frac{\alpha}{r^{K}}\right)^{\frac{\alpha}{1-\alpha}} a\left[a+(1-a)\left(\frac{1}{\phi^{L}}\right)^{\sigma}\right]^{\frac{1-\sigma}{\sigma}}=\left(\frac{\alpha}{r^{P C}}\right)^{\frac{\alpha}{1-\alpha}} b\left[b+(1-b)\left(\frac{1}{\phi^{H}}\right)^{\sigma}\right]^{\frac{1-\sigma}{\sigma}}
$$

and

$$
\left(\frac{\alpha}{r^{K}}\right)^{\frac{\alpha}{1-\alpha}}(1-a)\left[a\left(\phi^{L}\right)^{\sigma}+(1-a)\right]^{\frac{1-\sigma}{\sigma}}=\left(\frac{\alpha}{r^{P C}}\right)^{\frac{\alpha}{1-\alpha}}(1-b)\left[b\left(\phi^{H}\right)^{\sigma}+(1-b)\right]^{\frac{1-\sigma}{\sigma}}
$$

${ }^{10}$ We have chosen to present in the main text what we believe to be the simplest model that delivers the propositions which we investigate empirically. However, on some dimensions it is certainly too simplistic. For example, the particular formulation implies that adding more unskilled workers to a labor market while 
This forms the basis of Proposition 1.

Proposition 1: After the arrival of a PC-based, skilled-biased technology, the ratio of PCs per worker will be an increasing function of a locality's ratio of skilled to unskilled workers.

Proposition 1 indicates that skill biased technologies are adopted most aggressively by localities in which skill is relatively abundant, and therefore the observable aspects of the technology - such as here $P C$ capital - are most prevalent in localities with more skill. This implication is the focus of the Doms \& Lewis (2006) paper. Here, we want to go further and derive a set of additional implications in order to examine more closely the relevance of a biased technology adoption model for understanding differences in outcomes across localities. To this end, we first extend slightly Proposition 1 and derive a corollary that captures the incentive mechanism that lead to the different adoption decisions. Note that from an individual firm's perspective, the differential adoption decisions across localities must reflect different incentives induced by factor prices. In effect, in localities with initially high ratios of skilled to unskilled labor, the relative price of skilled labor is initially low (prior to the availability of the new technology), favoring the adoption of a technology which uses skill intensively. This implication is expressed in Corollary 1.

Corollary 1: The ratio of PCs per worker is an increasing function of a locality's initial ratio of skilled to unskilled wages.

Proposition 1 and Corollary 1 focus on the effects of local market condition on adoption decisions. We now want to change perspective and examine instead how the arrival of the new technology affects relative wages. In particular, we first want to emphasize how changes in the return to skill, as expressed by the change in the $(\log )$ ratio $\frac{w_{i}^{S}}{w_{i}^{U}}$, vary across localities faced with similar new options. This is captured in Proposition 2 and Corollary 2.

keeping the number of skill workers constant would lead to a decrease in the number of PCs. This implication is likely false as it results from the assumption that there is no possibility of using PCs in the traditional technology. A slightly generalized formulation, which reverses this implication, is one where the traditional technology use both structures and equipment. At $t=0$, the PC becomes available. The PC can then be used either as a substitute for equipment in the traditional technology, or it can be used in a new form of organization which is both skill-biased and uses PC more intensely than the traditional technology (is the sense that, as given factor prices, it uses a greater number of PC per worker). This later form of work organization is what we envision as the new technology. It can be easily verified that this alternative formulation is consistent which the all the propositions presented in the paper, but it does not imply that the number of PCs used would decrease with an increase in unskilled labor. 
Proposition 2: The arrival of the skilled biased technology causes the returns to skill to increase most in localities where skill is abundant.

The content of Proposition 2 can be obtained by deriving the relationship between the return to skill and the supply of skill before and after the arrival of the new technology, and taking the difference between the two. This relationship is expressed analytically below and graphically in Figure 2. As can be seen, for localities with very low initial supply of skilled workers, relative wages don't change since the new technology is not adopted. For localities, with $\phi^{H}<\frac{S_{i}}{S_{i}+U_{i}}$, they experience the largest increase in the returns to skill since they switch entirely to the new technology which acts as an increase in the demand for skill. Finally, for localities in partial adoption region $\phi^{L}<\frac{S_{i}}{S_{i}+U_{i}}<\phi^{H}$, the increase in the returns to skill in strictly increasing in the supply of skill since the endogenously induced demand for skill is increasing with skill.

$$
\begin{array}{rrrr}
\Delta \ln \frac{w_{i}^{s}}{w_{i}^{U}}= & 0 & \text { if } & \frac{S_{i}}{S_{i}+U_{i}} \leq \phi^{L} \\
\Delta \ln \frac{w_{i}^{s}}{w_{i}^{U}}= & (1-\sigma)\left[\log \frac{S_{i}}{U_{i}}-\log \phi^{L}\right] & \text { if } & \phi^{L}<\frac{S_{i}}{S_{i}+U_{i}} \leq \phi^{H} \\
\Delta \ln \frac{w_{i}^{s}}{w_{i}^{U}}= & (1-\sigma)\left[\log \phi^{H}-\log \phi^{L}\right] & \text { if } & \phi^{H}<\frac{S_{i}}{S_{i}+U_{i}}
\end{array}
$$

Proposition 2 expresses how the arrival of the new technology induces a positive association between the supply of skill and changes in returns to skills. However, the proposition bypasses the channel through which this arises and, in this sense, it represents a reduced form relationship. Corollary 2 addresses this issue by combining Propositions 1 and 2 to highlight how it is the adoption of the PC-intensive technology that leads to increases in returns to skill.

Corollary 2: Returns to skill increase most in localities which choose to use PCs most intensively.

Any approach taken to evaluate Corollary 2 must acknowledge the endogeneity between PCs and returns to skill. Corollary 2 implies that its is the adoption of PCs induced by differences in initial supply of skill (or initial returns to skill) that causes increases in returns to skill. Viewed in this light, Corollary 2 can be evaluated by employing an IV strategy where 
either initial (pre-PC-adoption) levels of skill or returns to skill are used as instruments for $\mathrm{PC}$-adoption in a regression of changes in the returns to skill on PC-adoption.

Figure 2: Effect of Initial Supply on Change in Relative Wage

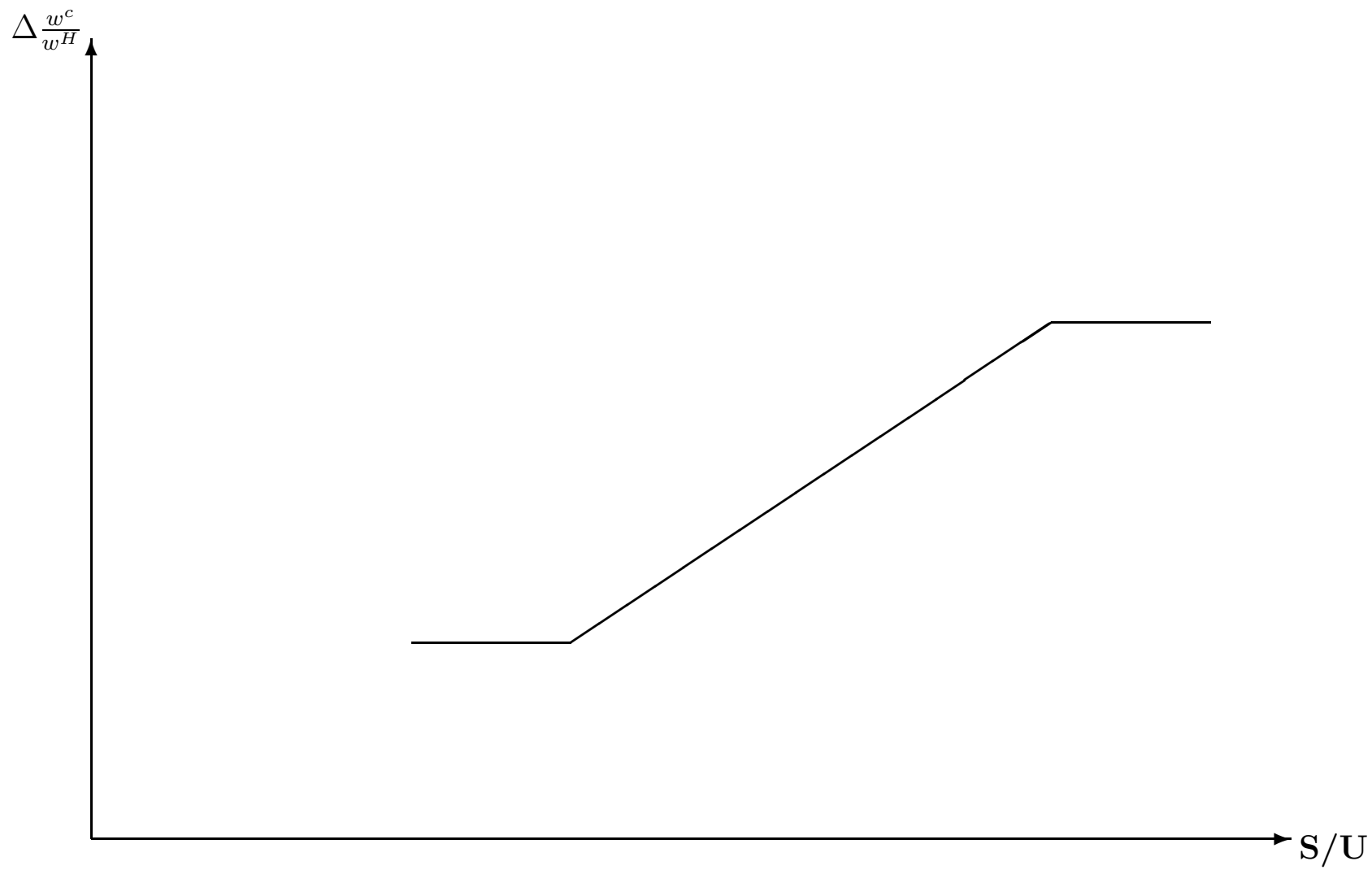

At first pass, Proposition 2 may possibly appear to contradict the law of supply and demand because it predicts an increase in return to skill where supply is most abundant. However, this is not the case since the model does not allow the level of the return to skill to be positively related to supply. In fact, as stated in Proposition 3, even after the introduction of the skill-biased technology, the returns to skill must remain a weakly decreasing function of the supply of skill. Note that it is possible for the arrival of the skill biased technology to cause the disappearance of a negative relation between return and supply if localities are concentrated in the technology-mixing zone $\left(\phi^{L}<\frac{S_{i}}{S_{i}+U_{i}}<\phi^{H}\right)$, since in this region there is factor price equalization. However, in the absence of any externalities in adoption, the model implies that the relationship between returns to skill and supply of skill cannot be positive even after the introduction of the skilled-biased technology. 
Proposition 3: The arrival of the skill biased technology cannot induce a positive association between the return to skill and the supply of skill.

The content of Propositions 2 and 3 can be easily inferred from Figure 1. Because the returns to skill in this figure are captured by the slope of the production function, we can note that the slope of the outer envelop is weakly decreasing in the fraction of skilled workers. This is the content of Proposition 3. In contrast, if we consider the change in the return to skill induced by the new technology for an initial supply in the region $\left(\phi^{L}<\frac{S_{i}}{S_{i}+U_{i}}<\phi^{H}\right)$, we see that the increase in the slope is larger for initial higher levels of supply. The reason is that the return to skill was initially more depressed in the higher supply localities and therefore the new technology allows for greater induced demand for skill in such areas. The content of Proposition 3 is depicted in Figure 3. In this figure we see that the availability of the new technology alters the relationship between returns to skill and supply. However, the slope of the new relationship is nowhere positive. Note that in the region $\phi^{L}<\frac{S_{i}}{S_{i}+U_{i}}<\phi^{H}$, the slope of the relationship is zero. This arises since the technological choice allows the reallocation of additional skill between the two technologies without affecting the returns. ${ }^{11}$

Now that we have examined the effects of supply on both adoption and wage change, we can therefore combine the two to obtain Corollary 3.

Corollary 3: The return to skill will not be larger in localities with more intensive use of PCs.

Corollary 3 indicates that although PC adoption and increases in the returns to skill should go hand-in-hand (as stated in Corollary 2), such positive co-movement cannot induce an outcome where the returns to skill are higher in a locality with a higher PC-intensity. The reason for this result comes directly from the fact that PC adoption is endogenous in the framework. To be more precise, PCs are adopted more aggressively in one locality versus another only because the cost of skill is lower. Therefore, PC capital cannot be more intensely used in a locality with a higher cost of skill. By contrast, if the adoption and subsequent use of PCs were viewed as an exogenous phenomena (as is the case in many papers), then it would be natural to expect to find a positive association with PC use and returns to skill (assuming that PCs are a skill-biased technology). Hence, this prediction nicely illustrates how a model of endogenous technology adoption differs from more conventional models with

\footnotetext{
${ }^{11}$ This mechanism is identical to that underlying factor price equalization zones in international trade theory.
} 
exogenous technological change. ${ }^{12}$

Figure 3: Effect of Supply on Relative Prices

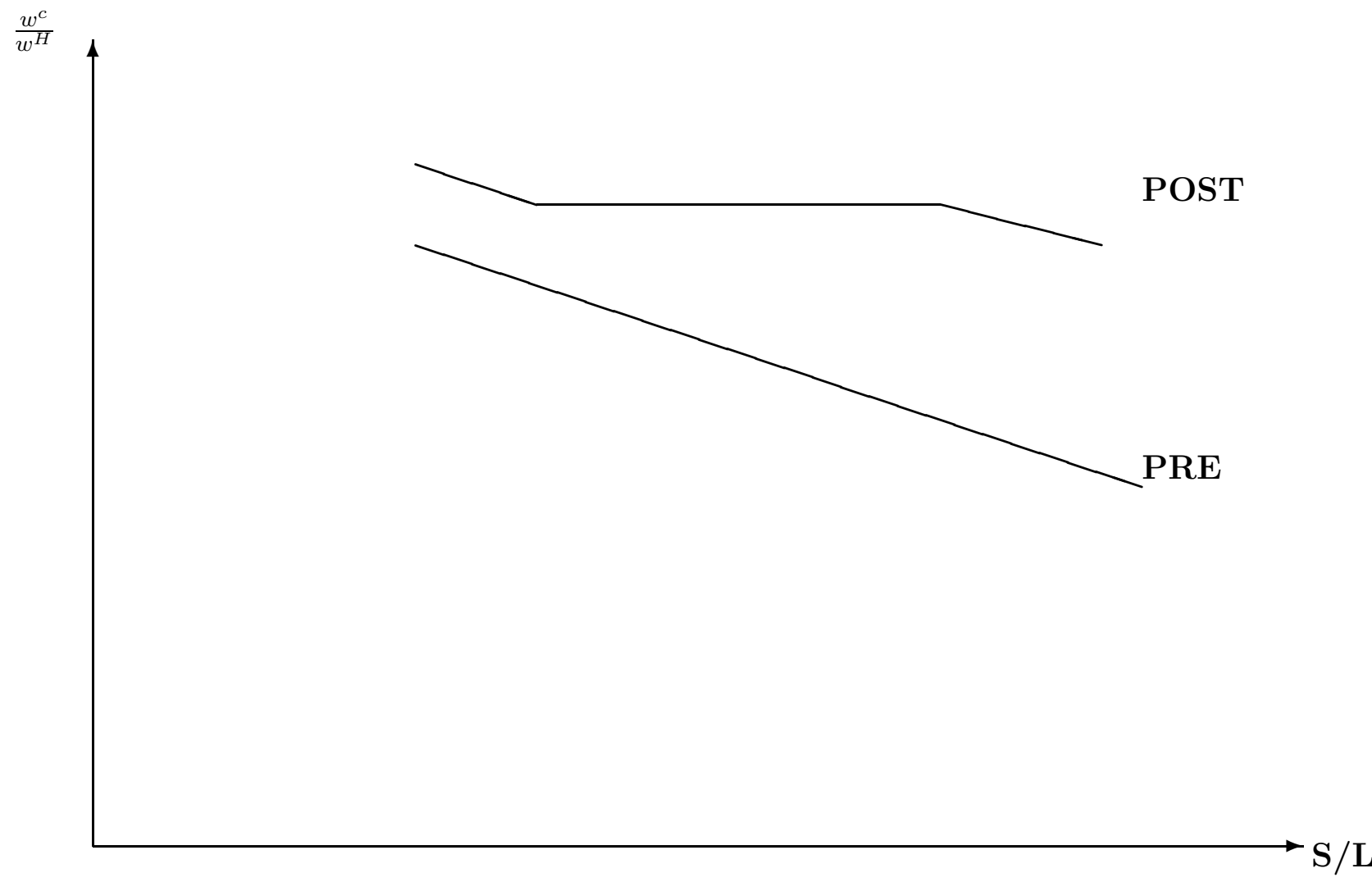

So far we have focused on the implications of the process of technology adoption on the returns to skill, but we have not examined implications for each component, that is, implications for changes in the the wage of skilled workers and wages of unskilled workers taken individually. Proposition 4 addresses this point.

Proposition 4: After the arrival of the skill biased technology, the wage paid to skilled workers should increase most in localities which adopt PCs most intensively, or alternatively in localities with either an initially low return to skill or a high supply of skill. Conversely, the wage paid to unskilled workers should decrease most in localities which adopt PCs most

\footnotetext{
${ }^{12}$ The implication of endogenous adoption stated in the previous propositions and corollaries would be modified if the adoption process involved externalities. For example, suppose there existed a network type externality associated with the adoption of the new technology, that is, suppose that as more local production was done with the new technology, the productive performance of the new technology increased. In such a case, it would be possible to have returns to skill being positively correlated to PC-intensity. Also, the returns to skill could be, at least over a range, an increasing function of the supply of skill.
} 
intensively, or alternatively in localities with either an initially low return to skill or a high supply of skill.

Proposition 4 indicates that the model of endogenous technology adoption predicts opposite responses for high skilled wages versus low skilled wages to local supply conditions. In particular, as in the case of Proposition 2, Proposition 4 predicts positive relationships between changes in wages for a skill group and its relative supply. The intuition is again simple. If a locality has an abundance of skilled workers, then it should adopt the new technology aggressively which induces an increased demand for skill and a substitution away from less skilled workers. If instead the locality has mostly unskilled workers, then it does not adopt the new technology intensely and hence such a locality should not experience a strong reduction in the demand for less skilled workers. As discussed in Section 5, the prediction that the adoption of PCs leads to a decrease in the wage of less skilled workers is a feature that will help differentiate the current model from alternative explanations.

So far we have emphasized the role of differences in skill mix at the city level on technology adoption and on the subsequent changes in wages. However, we have not offered any explanation for the observed difference in skill mix across cities (which are stark and are shown in the next section), we have simply noted that it predates the arrival of the PC and therefore may plausibly be taken as exogenous to the process of PC adoption. One possible reason for differences in skill mix across cities is the presence of amenities that act as luxury goods. As discussed in Black, Kolesnikova and Taylor (2004), such amenities can help explain differences in skill mix, differences in returns to skill and differences in housing prices across cities. In fact, the data patterns presented in this section can be shown to be consistent with an environment where (1) skilled workers are mobile across cities and land prices adjust to make such individuals indifferent between locations (as discussed in Black, Kolesnikova and Taylor (2004)), and (2) cities gained the option of adopting a PC and skill-intensive technology over the period 1980-2000. ${ }^{13}$ However, for simplicity we have not pursued this avenue here.

\footnotetext{
${ }^{13}$ Another possible reason for differences in skill levels across cities are differences in industry composition. However, as shown in Doms and Lewis (2006), industry composition accounts for very little of the crosssectional variation in skill levels.
} 


\section{Data}

Section 2 highlighted several implications of viewing technological adoption as driven by principles of comparative advantage. Our goal now is to examine whether city-level outcomes observed over the 1980-2000 period exhibit the patterns implied by such a model. We choose to focus on this period for several reasons. First, this is a period often referred to as one of technological revolution due to astounding technical progress and diffusion of information technology. Hence it is a perfect candidate period to see whether our neoclassical model of technological adoption is relevant. Second, it is a period in which returns to education have increased substantially, for which skill-biased technological change is a primary suspect. Therefore, it is particularly relevant to examine whether this period is best characterized as reflecting the effects of exogenous technological change (in line with much of the literature which treats the extent and bias of technological change as an exogenous driving force) or whether instead it reflects a process of endogenous choice of production techniques. ${ }^{14}$

The city-level data we use can roughly be divided into two categories; technology and demographic. The technology data is derived from establishment-level information on technology use and is described in more detail in Doms and Lewis (2006). About 160,000 establishmentlevel observations per year are used to compute the PC intensity (PCs per employee) of each city in our sample (230 cities). ${ }^{15}$ Our PC intensity measure is an industry-adjusted measure; in computing the PC intensity, we control for the 3-digit SIC industry interacted with 8 establishment size classes, for a total of over 1,800 interactions. $^{16}$

We focus on PCs instead of other IT technologies for several reasons. First and foremost, businesses spent about 90 percent more money on PCs during the 1990s than on other types

\footnotetext{
${ }^{14}$ Note that it could be possible that the extent of bias of technical change is endogenous at the national level, but not at the city level since markets across cities are well integrated. In such a case, our approach of focusing on city level outcomes would not identify elements of endogenous technological change. In other words, our empirical work evaluates the joint hypothesis that technological adoption is a phenomena that reacts to market conditions and that the labor markets in cities across the US are not perfectly integrated.

${ }^{15}$ To increase the precision of our city-level measures, the 1990 PC intensity measure uses data from 1990 and 1992 and the 2000 PC intensity measure relies on 2000 and 2002 data. Doms and Lewis (2006) define "city" primarily as consolidated metropolitan statistical areas (CMSAs). The logic was to derive city definitions that corresponded to the idea of a local labor markets. In some cases, CMSAs were modified to more closely capture the concept of a labor market. Our results throughout the paper are insensitive to how we define labor markets in especially large, contiguous areas, such as in and around New York City.

${ }^{16}$ The SIC-size interaction allows for the possibility that, for instance, large banks perform different operations than small banks. As described in Doms and Lewis (2006), our city-level measures of PC intensity are strongly correlated with other measures that control for 4-digit SIC and for measures that also control for the firm to which an establishment belongs.
} 
of computers. Also, spending on PCs is likely correlated with other information technology spending, such as spending on software, computer networking equipment, printers, et cetera. Finally, we were able to obtain consistent measures of PCs over this period. ${ }^{17}$

Figure 4 shows a scatter plot of the city-level PC measures for 1990 and 2000 (the 1990 results are shown along the horizontal axis and the 2000 results are shown on the vertical axis). The axes in figure 4 are scaled to the San Francisco Bay Area, the city that consistently ranked very highly in nearly all measures of technology that we have examined. For instance, in 1990, the mean establishment in San Francisco had .12 more PCs per employee than the mean establishment in Scranton, PA (the city that frequently ranked among the lowest of our sample of cities) after controlling for industry and size differences across the two cities. In 2000, the difference in PC intensity between the Bay Area and Scranton increased to .16. One item to note about figure 4 is that the differences in PC intensity are persistent over time: for example, the correlation in PC intensity between 1990 and 2002 is $0.57{ }^{18}$

Most of the city-demographic information we use comes from the decennial censuses, specifically the public-use micro-data files for 1970, 1980, 1990, or 2000. The thrust of our analysis is to examine how the technology measures discussed above correspond to relative supplies of skilled labor and to relative wages. Our measure of skilled labor is defined as workers who have a least a four year college degree plus one-half of those with at least some college education. Measures similar to this one are often used in research examining the impact of skill-biased technological change, such as Katz and Murphy(1992), Autor et al.(2003), and Card and DiNardo(2002)..$^{19}$

The measure of skill varies greatly across cities, but the ranking of cities according to skill remains nearly constant over time. Figure 5 shows a scatter plot of the log of skilled to unskilled workers for 1980 and 2000. As with the PC intensity data, there is great persistence in the skill mix over time as the skill mix in 1980 explains over 85 percent of the variance in 2000, although the mean skill share increases sharply. Doms and Lewis (2006) finds that one reason why the skill mix for a city changes by more or less than average is immigration.

\footnotetext{
${ }^{17}$ Other measures of information technology were examined in Doms and Lewis (2006), including more refined measures of PC. The results in Doms and Lewis (2006) were very robust to choice of technology measure. However, our wage measures do not account for occupational differences, one of the areas we plan to pursue in future research.

${ }^{18}$ The PC debuted in 1981. To obtain a measure of information technology before the introduction of the PC, Doms and Lewis (2006) used data on IT sales by city between 1978 and 1980. The correlation between these IT sales data and PC intensity in 1990 was close to 0.

${ }^{19}$ Further, our sample of workers includes employed 16-65 year-olds with at least one year of potential work experience and not living in group quarters.
} 
Cities such as Fresno, Stockton, and El Paso received relatively large numbers of unskilled immigrants over the past several decades, resulting in lower than average skill appreciation.

Our measure of relative wages is computed using the wages of people who report exactly a high-school degree or GED and people with exactly a four years of post high school education. We adjusted wages for each group by controlling for a fourth-degree polynomial in potential work experience, a female dummy, an immigrant dummy, and a dummy for people born after 1950. Although the results presented in subsequent tables use these adjusted relative wages, the results are robust to using non-adjusted wages as well.

We also construct several city-level measures that we label as city controls. These measures include the log of the size of the labor force and percent of the workforce in a city are African American, female, Hispanic, and U.S. citizens. Additionally, we construct 9 industry controls which reflect the employment distribution across major industry groups within each city.

In the empirical work that follows, it is necessary for us to use instruments that are correlated with the human capital in a city but not correlated with any of the unobserved determinants of technology adoption. Instruments used in Doms and Lewis (2006) relied on the historical density of colleges in an area. There are three reasons why the presence of colleges in an area may increase the general skill level of that area. The first is that the presence of colleges in an area reduces the cost of obtaining higher education for an area's residents. Second, college graduates may more likely settle in areas where they went to school as a result of low search costs. Finally, areas that have an abundance of colleges may also have amenities that college graduates place relatively high values on. ${ }^{20}$ One instrument we use, following Moretti (2004), is a dummy for whether or not the metropolitan area has a land-grant college. Landgrant colleges came into existence after Congress in 1862 passed the Morrill Act, which gave states land to fund the creation of university-level agricultural schools. Doms and Lewis (2006) shows that areas with land-grant colleges tend to have a significantly higher collegeeducated share. In addition to the information on land-grant colleges, we also use lagged information on local college density generally. There has been a dramatic growth in twoyear colleges since World War II (documented in Kane and Rouse, 1999) which may have raised educational attainment in areas which received new schools. To capture the effect non-land-grant may have on the local college share, we construct additional instruments

\footnotetext{
${ }^{20} \mathrm{As}$ a result, human capital theory predicts otherwise similar individuals will have higher college attainment (Card, 1999). At an individual level, for example, several studies have showed that the distance a person lives from a college when they are growing up predicts their college attainment (e.g. Kane and Rouse, 1995; Card, 1995).
} 
using information on enrollment at two- and four-year colleges in 1971 in each metropolitan area. $^{21}$

\section{Empirical results}

Our presentation of empirical results closely follows the order of the Propositions and Corollaries presented in Section 2. We begin by examining the determinants of technology adoption as measured by diffusion of PCs (Proposition 1). The first results echo those presented in Doms and Lewis (2006). We then go further by examining whether returns to skill in 1980, at the beginning of the diffusion process for PCs, are negatively associated with the intensity of PC use in 2000 (Corollary 1). We next turn to examining implications of the model for changes in the returns to skill, as measured by the ratio of college wages to high school wages. In particular, we explore whether the data exhibits a positive co-movement between PC-adoption and changes in the returns to skill as implied by Corollary 2, but do not reveal a positive association between the level of returns to skill and PC use as implied by Corollary 3. We also report the reduced form implications of the model regarding the changes in the returns to skill and the supply of skill (Proposition 2), in addition to examining changes in the relationship between the level of return and the supply of skill (Proposition 3). Finally, we examine the relationship between PC-adoption and changes in the wages paid to high school workers and college workers separately (Proposition 4).

\subsection{PC adoption and local market conditions}

To begin and to illustrate the strength of the relationship between PC adoption and skills, Figure 6 shows a scatter plot of PC intensity against the log ratio of skilled versus unskilled labor for 2000. To examine the relationship between these variables more rigorously, Table 1 reports a series of regression results. The first column of Table 1 reports the results obtained by regressing our city-level measure of PCs-per-worker on the log ratio of college to high school equivalent workers. As can be seen from the table, cities with a high fraction of college educated workers in 2000 also had adopted PCs more intensively by the year 2000 .

\footnotetext{
${ }^{21}$ Doms and Lewis (2006) also examine instruments based on immigration patterns for the change in college share. Doms and Lewis (2006) find very similar results in PC adoption equations between the college-based instruments for the level of human capital and the immigrant-based instruments for the change in human capital.
} 
The data in Figure 6 demonstrate that the relationship is not driven by outliers. Since cities that use information technology more intensively may attract higher educated workers, this observation does not imply that the local supply of college educated workers caused a greater adoption of PCs. In order to address the possibility of reverse causation, Column 4 reports an estimate obtained by instrumental variables, where the instruments, which are described more fully in the previous section, correspond to measures of local college accessibility and attendance as of 1971, which is well before the availably of PCs. ${ }^{22}$ The IV estimate is almost identical to the OLS estimate, suggesting that the endogeneity of worker migration cross cities to take advantage of more IT intensive cities may not be very strong.

Columns 2,3,5 and 6 follow up on this conjecture by breaking down the local skill measure into its level in 1980 (just before the introduction of the IBM PC) and its change between 1980 and 2000. The only difference between columns 2 and 3, and between columns 5 and 6 , is the addition of a set of city level controls. ${ }^{23}$ The estimates in columns 2 and 3 are obtained by OLS, while those in column 5 and 6 are obtained by IV. The results reported in Column 5 and 6 are based on the same 1971 variables to instrument both the the level and the change in skill supply. Note that if the supply of skills is exogenous to the process of technology adoption, then the coefficients on both the 1980 level of skill and the change in skill between 1980 and 2000 should have the same size coefficient, and this is what is observed in all but one case $^{24}$ Furthermore, the estimates obtained by OLS and IV are very similar adding support to the notion that it is the local supply of skill that favored differential adoption patterns across US cities and not the reverse. ${ }^{25}$ While there are many models or mechanisms of technological change that could potentially explain the observations presented in Table 1, our goal now is to examine whether the mechanism outlined in the theory section is relevant by examining implications for wages.

The estimates presented in Table 1 indicate that cities with a more educated labor force as of 1980 adopted PCs more aggressively between 1980 and 2000. The neoclassical model presented in Section 2 suggests that such an outcome arises due to the price incentive by firms in cities with initially expensive low skilled workers (relative to high skilled workers) to adopt skill-biased technologies. ${ }^{26}$ In Table 2 we examine whether the data support such a

\footnotetext{
${ }^{22}$ The first stage had an $r^{2}$ of .32 .

${ }^{23}$ The city level controls correspond the size of the labor force, unemployment rate, the fraction of population which is female, percent African-American, and U.S. citizens.

${ }^{24} \mathrm{We}$ tested the equality of these coefficients, and the p-values are reported on the last row of the table.

${ }^{25}$ Recall that the measure of city-level PC-use we use controls for a cities industrial composition.

${ }^{26} \mathrm{~A}$ clear negative trend between relative wages and the supply of skilled labor for 1970, 1980 and 1990 is
} 
mechanism by regressing PC intensity in 2000 on the relative cost of skilled versus unskilled labor in 1980. As can be seen in Column 1, cities with low relative cost of skills in 1980 are observed to be using PCs more intensively as of 2000. In the second column, we add the change in the ratio of college and high-school educated workers, and in column 3 we also control for share of employment at the industry level (in two digit industries). In the fourth column, we instrument the change in the ratio of college to high school educated workers, again using 1971 college attainment and access variables as instruments. In all cases, we find that the return to skill as of 1980 has a significant negative effect on subsequent PCadoption. We also find that after controlling for initial returns to skill, an increase in the college population favors more PC-adoption. Once again we find only minor differences between treating changes in the college population as exogenous to the adoption process as compared with estimating by IV, further suggesting that the endogeneity of skill supply to PC-adoption process is likely minor.

\subsection{Returns to skill and PC adoption}

We now turn to the relationship between the adoption of PCs and changes in the returns to skill. Recall that our model implies a positive association between these two endogenous variables. In Table 3 we report results obtained by regressing the change in the return to skill over the period 1980-2000 on the extent of PC-adoption in 2000. In the first 3 columns we estimate the relationship by OLS, which likely provides a downward biased estimate due to the endogeneity of PC-use. In particular, given our theoretical framework, we expect that unobserved variables which lead to higher returns to skill would result in lower PC adoption. As can be seen, our OLS results find a positive, but weak and insignificant relationship between these two variables. In columns 4 to 6 , we report IV estimates where we instrument the $\mathrm{PC}$-adoption variable by the 1980 ratio of college educated workers to high school educated workers. As shown in Table 1, the first stage of this regression works well. The IV results indicate a strong positive association between PC-adoption and changes in returns to skill, even after including city and industry controls. We also estimated (but did not report here) the relationship using as an instrument the 1980 value of the returns to skill (as suggested by Table 2). In this case, we also found a very significant and robust positive relationship between changes in returns to skill and PC-adoption. The estimates shown by the scatter-plots in figures $8 \mathrm{a}-8 \mathrm{c}$. 
are bigger than the ones reported in Columns $4-6$, but are less precise. ${ }^{27}$

In addition to predicting that localities that adopt PCs intensively should witness greater increases in returns to skill, the model also predicts that the adoption process should not lead to a situation where returns to skill are higher in cities that adopted PCs most intensively. To examine this implication of the model, Table 4 reports estimates of the relationship between returns to skill in 2000 and the use of PCs in 2000. The first 3 columns report results based on estimating the relationship by OLS, and in the last three columns the relationship is estimated by IV, where the ratio of college to high school equivalent workers in 1980 is the instrument. In none of these cases do we observe a positive relationship between PC-use and returns to skill; in some cases we actually find a significant negative relationship. Taken together, the results in Tables 3 and 4 provide considerable support for the view that PCadoption and changes in returns to skill should be viewed as jointly determined, and that the process appears to conform to the neoclassical principles outlined in Section 2.

\subsection{Reduced form relationship between returns and skill supply}

Tables 3 and 4 report results associated with examining the implications of the model as stated in Corollaries 2 and 4 . For completeness, it is also of interest to directly examine the reduced form relationship emphasized by Proposition 2 and 3. To this end, we begin by showing a plot, Figure 7a, of the changes in the returns to skill and the initial supply of skill. As can be seen, there is a clear positive relationship with a regression slope coefficient of .07 and standard error of .01. Figures $7 \mathrm{~b}$ and $7 \mathrm{c}$ decompose the changes by decade and show that the change in relative wages between 1980 and 1990 had no significant relationship vis-a-vis skill share, whereas the change in 1990-2000 had the most pronounced relationship with skill share. ${ }^{28}$ This suggests that PC adoption may have been a much more important force in explaining changes in wage differentials movements in the 1990s then during the introductory phase of the 1980. Turning to a fuller set of regressions, the first three columns of Table 5 report the results of regressing change in the returns to skill over the period 1980 to 2000 on the 1980 ratio of college to high school educated workers and the change in skill

\footnotetext{
${ }^{27}$ As a robustness check, we ran the regressions in Table 3 separately for the change in relative wages of men only and women only. The results for each group were similar to those reported in Table 3 although the results for women were, on average, a bit stronger than those for men.

${ }^{28}$ As we have mentioned previously, the PC was introduced in 1981, and hence we frequently begin our analyses with data in 1980. However, it was not until the 1990s that information technology became a significant share of the capital stock and a significant contributor to GDP growth.
} 
supply over the period 1980-2000.

In order to better interpret the coefficients on the initial supply of skill and the coefficient on the change in the supply of skill, it is helpful to recall that the theory implies that the arrival of a skilled biased technology will cause a flattening of the relationship between the returns to skill and the local supply of skill (as depicted in Figure 3). If we approximate this prediction by a change in the linear relationship between return and relative supply, then we can see that theory predicts the change in the returns to skill to be positively related to the initial level of skill and negatively related to the change in skill. In order to see this more clearly, let us express the initial relationship between return and supply by:

$$
\frac{w_{i, 0}^{S}}{w_{i, 0}^{U}}=\alpha_{1}+\alpha_{2} \frac{S_{i, 0}}{U_{i, 0}}
$$

and denote the relationship after the arrival of the technological option by:

$$
\frac{w_{i, 1}^{S}}{w_{i, 1}^{U}}=\beta_{1}+\beta_{2} \frac{S_{i, 1}}{U_{i, 1}}
$$

where $\alpha_{2}<\beta_{2} \leq 0$.

Then the change in the returns to skill is then given by

$$
\Delta \frac{w_{i}^{S}}{w_{i}^{U}}=\left(\beta_{1}-\alpha_{1}\right)+\left(\beta_{2}-\alpha_{2}\right) \frac{S_{i, 0}}{U_{i, 0}}+\beta_{2} \Delta \frac{S_{i}}{U_{i}}
$$

with $\beta_{2}-\alpha_{2}>0$ and $\beta_{2} \leq 0$. In words, the coefficient on the initial supply should capture the change in the slope of the relationship between return and relative supply of skill-which the theory predicts in positive - and the coefficient on the change in supply should capture the final slope- which according to the theory could be either negative or zero in the absence of externalities.

Interestingly, the results in Columns 1-3 of Table 5 indicate a positive relationship between the change in returns and the initial supply of skill, while simultaneously observing a negative or zero relationship between the change in returns and the supply of skill. In fact, the latter relationship is sufficiently weak to suggest it may be a zero relationship. The last three columns examine the effect of replacing the initial skill ratio with the initial value of the 
returns to skill, as also suggested by Proposition 2. Here we see, consistent with the theory, that returns to skills increased most in cities where the returns were initially low.

The results presented in Table 5 were aimed at evaluating the implications of Proposition 2. The goal of Figure 8 and Table 6 is to examine more directly the local flattening of the relationship between returns to skill and supply of skill implied by the theory. To this end, Figure 8 plots the relative wages and the supply of skill for 1970, 1980, 1990 and 2000 and Table 5 reports the associated regression estimates. From the figures and the table we can see that the slope of the relationship between returns to skill and the supply of skill is significantly negative in 1970, 1980 and 1990. ${ }^{29}$ By contrast, in 2000 the returns to skill/supply of skill relationship essentially evaporates at the local level. This finding is consistent with Proposition 3 if cities are finding it optimal to simultaneously use both old and new technologies. Note that these observation are also consistent with those presented in Table 5, which can be viewed as providing first difference estimates of both the slope in 2000 (through the coefficient on the change in supply of skill) and the change in the slope between 1980 and $2000 .^{30}$

\subsection{Changes in wages and PC adoption}

In order to complete our exploration of the implications derived in Section 2, namely Proposition 4, Table 7 displays results of changes in college and high school real wages separately. In this table we see that the growth in wages of high school educated workers (in columns 1,3 and 5) was negatively associated with the extent of PC adoption within cities, and this pattern is observed whether the relationship is estimated by OLS or by IV using the city level market conditions in 1980 as instruments for PC adoption. Note that this result is not implied by the previous results since high school educated workers could have made wage gains in cities that adopted PCs aggressively while allowing college educated workers to do even better. However, this is not what is observed. Instead, consistent with the theory, we

\footnotetext{
${ }^{29}$ Because of data issues, we could only focus only on 140 of our 230 sample of our cities for 1970.

${ }^{30} \mathrm{An}$ alternative explanation for such convergence is that the supplies of skills converges across cities. However, there was actually only minimal convergence in the fraction of college equivalent workers across cities over this period, with the variance of the fraction college equivalents per city being almost the same in 2000 as in 1980. This contrasts with Glaser (2005) which reports a divergence in the concentration of college educated over this period. His result relies on looking precisely at the fraction of workers with 4 years of college or more. If instead we look at the fraction of college equivalents, where workers with post secondary education are allocated equally between high skill and low skill, then there is no indication of either convergence or divergence. Finally, if we look at the log of the ratio of college equivalents to high school equivalents, there is evidence of convergence but the coefficient is nowhere near -1 .
} 
see that high school educated workers were negatively affected by the adoption of PC in an absolute sense, not just a relative sense.

For college educated workers, the OLS results do not uncover much of a relationship between their wage change and the adoption of PCs. However, since both variables are endogenous, the coefficient can be expected to be biased. Accordingly, we also report results where we instrument the extent of PC-adoption by the ratio of college and high school educated workers in 1980 and the return to college in 1980 (using only one of these instruments gives similar, but slightly less precise, estimates). The IV results indicate that college educated workers had faster wage gains in cities that adopted PCs most intensely, nearly to the same extent that high school workers lost. ${ }^{31}$

\section{$5 \quad$ Alternative explanations}

The evidence presented in Tables 1 to 8 provide considerable support for the model of endogenous technology adoption we presented in Section 2. However, such evidence does not imply that this model is correct since the data may be consistent with alternative interpretations. In this section we compare the properties of our model to several alternative technology specifications used in the literature. We then examine two non-technological explanations for our results; increased labor mobility and increased trade.

\subsection{A comparison to other technology specifications}

We ask whether the observed patterns can be easy explained by alternatives suggested by the literature. One class of explanations we want to examine focuses upon the effects of a fall in the price of equipment - such as PCs - within a stable production function framework. To be more precise, let us continue to consider an environment with four factors of production: traditional capital $(K)$, PC/equipment $(P C)$, skilled labor $(S)$ and unskilled labor $(U)$. However, instead of considering two production functions, let us postulate a unique production function denoted by $f\left(K_{t}, P C_{t}, S_{t}, U_{t}\right)$, with wages for skilled and unskilled labor given by the marginal products. The issue we want to address is whether the cross-city patterns

\footnotetext{
${ }^{31}$ The result for college wages is robust to a wide variety of specifications, especially for specifications that examine the changes in wages in the 1990s. The results for high school wages are somewhat less robust, but, the high school wage results always imply a zero to negative relationship with PC adoption, a result in stark contrast to that for college wages.
} 
we have documented can be explained within this alternative framework as the result of a common fall in the price of $\mathrm{PC} /$ equipment. If we impose no restrictions on the function $f(\cdot)$, the answer to this question is a trivial yes since the stable production needs to be chosen as the outer envelop of our two production function setup. ${ }^{32}$ Hence, to make this question relevant, we need to ask whether the observed patterns could be explained by commonly used parameterizations for such a function. To this end, we will focus on three nested CES specifications.

The first parametrization we consider, denoted by $f^{I}$, is in the spirit of the work by Katz and Murphy (1992). In this case, the two types of capital form a sub-aggregate and the two types of labor form a sub-aggregate. The function $f^{I}(\cdot)$ can then be represented by

$$
f^{I}\left(K_{t}, P C_{t}, S_{t}, U_{t}\right)=\left[K_{t}^{\sigma}+P C_{t}^{\sigma}\right]^{\frac{\alpha}{\sigma}}\left[S_{t}^{\gamma}+U_{t}^{\gamma}\right]^{\frac{1-\alpha}{\gamma}}
$$

In the second case $\left(F^{I I}\right)$, motivated by the capital skill-complementarity hypothesis, we allow $P C$ capital to be a complement to skilled labor. This case is represented by the following production function

$$
f^{I I}\left(K_{t}, P C_{t}, S_{t}, U_{t}\right)=K_{t}^{\alpha}\left[\left[S_{t}^{\sigma}+P C_{t}^{\sigma}\right]^{\frac{\gamma}{\sigma}}+U_{t}^{\gamma}\right]^{\frac{1-\alpha}{\gamma}} \quad \sigma<0
$$

The third possibility is motivated by Autor, Levy and Murnane (2003) which emphasizes the substitution between PCs and unskilled workers. In this case, the production function takes the form

$$
f^{I I I}\left(K_{t}, P C_{t}, S_{t}, U_{t}\right)=K_{t}^{\alpha}\left[\left[U_{t}+P C\right]^{\gamma}+S_{t}^{\gamma}\right]^{\frac{1-\alpha}{\gamma}}
$$

Given that we want to consider the situation where firms at the city level can rent both types of capital on a common market, it is useful to define a reduced form production function $\tilde{f}^{i}, \quad i=I, I I, I I I$, which represents the production possibility set at the city level, as follows

\footnotetext{
${ }^{32}$ Given that there is a fundamental observational equivalence between a choice of technique framework and a stable production function framework, one may ask what is the advantage of the choice of technique framework. One answer is that the endogenous choice of technique framework leads one to consider parameterizations of the aggregate production function which otherwise would appear bizarre, un-intuitive and would therefore likely be overlooked. By contrast, when such parameterizations are presented through the lens of the endogenous technological adoption framework, they become intuitive and credible contenders as explanations to observations.
} 


$$
\tilde{f}^{i}\left(r_{t}^{K}, r_{t}^{P C}, S_{t}, 1-S_{t}\right)=\max _{K_{t}, P C_{t}} f^{i}\left(K_{t}, P C_{t}, S_{t}, 1-S_{t}\right)-r_{t}^{K} K_{t}-r_{t}^{P C}
$$

and let us denote by the function $\tilde{P C}{ }^{i}\left(r_{t}^{K}, r_{t}^{P C}, S_{t}, 1-S_{t}\right)$, the optimal choice of $P C$ equipment per worker for a city with a fraction $S_{t}$ of skilled workers and a fraction $1-S_{t}$ of unskilled workers. In order to be consistent with the observations presented in Tables 1-7, the functions $\tilde{f}^{i}(\cdot)$ and $\tilde{P C}^{i}(\cdot)$ need to satisfy at least three properties. First, $\tilde{P C}^{i}(\cdot)$ should be such that the number of PCs per worker increases with the fraction of the work force that is skilled. This requirement is necessary in order to be consistent with with the observations of Table 1. The next two requirements are that, following a decrease in the rental price of $P C$ s, $r^{P C}$, the change in the wage of skilled workers should be greatest in cities where the ratio of $\frac{S}{U}$ is high, and the change in the wage of less skilled workers should be negatively related to the skill ratio. These conditions guarantee consistency with the results of Table 7 and therefore consistency with Tables 3 and 5 . These two last conditions can be seen as restrictions on the cross-derivative of the functions $\tilde{f}^{i}(\cdot)$. In particular, to satisfy these conditions it is necessary that (1) the second derivative of wage of skilled workers (where the wage of skilled workers can be denoted $\left.\tilde{f}_{3}^{i}()\right)$ with respect to the rental cost of computers and to quantity of skilled workers be negative, and (2) the second derivative of wage of unskilled workers (where the wage of unskilled workers can be denoted $\tilde{f}_{4}^{i}()$ ) with respect to the rental cost of computers and to quantity of skilled workers be positive. These two conditions are expressed below.

$$
\begin{aligned}
& \frac{\partial^{2} \tilde{f}_{3}^{i}\left(r_{t}^{K}, r_{t}^{P C}, S_{t}, 1-S_{t}\right)}{\partial r^{P C} \partial S}<0 \\
& \frac{\partial^{2} \tilde{f}_{4}^{i}\left(r_{t}^{K}, r_{t}^{P C}, S_{t}, 1-S_{t}\right)}{\partial r^{P C} \partial S}>0
\end{aligned}
$$

For all three parameterizations, the function $\tilde{P C}^{i}\left(r_{t}^{K}, r_{t}^{P C}, S_{t}, 1-S_{t}\right)$ will generally exhibit the property that the number of $P C$ s per worker is increasing in the fraction of skilled workers. Hence, the results of Table 1 would be consistent with either of these models in addition to our choice of technique model. However, it can be verified that none of these parameterizations can simultaneously satisfy all three conditions. For case I, the accumulation of $P C$ capital has a similar effect on the wages of both skilled and unskilled workers. In case II, when $P C$ capital increases with the ratio of skilled to unskilled, then the condition $\frac{\partial^{2} \tilde{f}_{4}^{i}\left(r_{t}^{K}, r_{t}{ }^{C}, S_{t}, U_{t}\right)}{\partial r^{P C} \partial S}>0$ 
will not be satisfied due to the fact that increases in $P C$ capital leads to an increase in the wage of less skilled workers. In case III, the change in relative wages due to a change in the cost of PC is independent of of local factor supplies (as in case I), and accordingly can not satisfy the conditions. Hence, these standard parametrizations of the aggregate production function are not sufficiently flexible to offer an explanation of our set of observations, which are easily explained with an endogenous technology model.

\subsection{Labor mobility and trade}

We now briefly examine the possibility that our cross-cities observations could be primarily driven by some non-technological forces as opposed to the technological forces emphasized by the model. In particular, we want to ask whether the observed patterns could be easily explained by either an increase in labor mobility across cities or by increased goods market integration (freer inter-city trade).

Let us start with labor mobility. One reason why there are less systematic differences in returns to skill across cities in 2000 than in 1980 could be that labor mobility across cities has increased; for instance, highly skilled individuals may have moved between cities where skill is abundant to where it was relatively scarce. There are two problems associated with this conjecture as an explanation to the observed patterns. First, it does not appear that labor flows were in a direction that would favor convergence. For example, the correlation between the change in college equivalent share by city over the period 1980-2000 with the initial level of the college equivalent share in 1980 (or the return to skill in 1980) is very close to zero. ${ }^{33}$ This is not surprising given that figure 5 showed very strong persistence in the skill levels across cities from 1980 to 2000. Furthermore, if labor mobility were the dominant force favoring a convergence in returns to skill across cities over this period - as opposed to different speeds of technology adoption - we would not expect to observe the patterns presented in Table 5. Recall that Table 5 showed that changes in the college-high school wage differentials over 1980-2000 were positively and significantly related to the fraction of college workers in 1980 and only weakly related to the change in the education composition of the city.

A second mechanism that could remove systematic differences in returns to skill across cities

\footnotetext{
${ }^{33}$ Barry and Glaeser (2005) actually suggest that flows favored divergence. The difference with the result reported here is they did not include any of the workers with post-secondary education in their measure of skilled workers, while our college equivalent share measure includes a fraction of post-secondary workers.
} 
is increased trade between cities. If the cost of trading between cities diminished significantly over the period, this should favor a reallocation of industries to take advantage of differences in skill supply across cities, thereby leading to factor price equalization. Taking this argument to the next logical step then, it should also be the case that the local industry mix will become more sensitive to the local factor endowments mix, as localities adapt industry mix to their comparative advantage. We evaluate that possibility with the following statistic:

$$
\sum_{j} \frac{C E_{j}}{N_{j}}\left[\Delta\left(\frac{N_{j, c}}{N_{j}}\right)-\Delta\left(\frac{N_{j}}{N}\right)\right]
$$

where $\frac{C E_{j}}{N_{j}}$ is the college equivalent share for industry $\mathrm{j}$ in 2000 and the term in brackets is equal to the change in employment share in industry $\mathrm{j}$ and city c compared to industry $\mathrm{j}$ in the nation as a whole between 1980 and 2000. This statistic tells us how much changes in industry mix in c are expected to increase college share in c. If geographic integration is occurring, then this statistic will be high for cities with a high college share, as collegeintensive industries disproportionately relocate to them, and low for cities with a low college share.

In order to evaluate the extent to which this is the case, Figure 9 plots this statistic against 1980 college equivalent share (normalized to zero for the average city, i.e. the "excess" college share). Note that this statistic is generally quite small - changes in industry mix have virtually no differential impact on changes in college share in most cities - and there is no sign that this relates positively to college share. For instance, one of the least educated cities in our sample, Scranton, PA, has one of the larger increases in college-intensive industry shares between 1980 and 2000. More generally, the coefficient from the regression line can be interpreted as the proportion of differences in college share absorbed by changes in industry mix: it is -.01 with a standard error of $0.01 .{ }^{34}$ Thus, at the level of industry detail available in the censuses, there is no evidence that cities are "integrating" over time. ${ }^{35}$ This is consistent with Lewis (2003) and Card and Lewis (2006) who find, using a similar approach, that industry mix accounts for little of the skill mix differences across cities.

Another difficulty with the increased inter-city trade explanation is that, controlling for

\footnotetext{
${ }^{34}$ The regression used the same weights used in the regression presented in tables 1-7.

${ }^{35}$ Industry mix is measured at the level of detail available in the 1980 PUMS, which is roughly equivalent to the 3-digit SIC. We used the same mapping of Lewis (2003) to match the industry codes in the 1980 and 2000 Censuses.
} 
industry structure, there should be no systematic differences in PC-use across cities: cities with more educated workers should have more skill and PC intensive industries but should not use PCs more intensively within an industry. However, as documented in Table 1 and illustrated in Figure 6, there is a strong positive link between PC use within industries and the local supply of skill.

\section{Conclusion}

In this paper we began by highlighting the implications of a simple neoclassical model of endogenous technology adoption. This model generates a number of predictions that we test using a dataset on technology, skills, and wages for a set of 230 cities during the IT revolution. We found the predictions of the model to conform well with the patterns found in the data.

One important aspect of the model and the empirical results is that they tie together two rather disparate strands of the literature. One strand has focused on how technological change affects the demand for skilled labor while the other has examined how the supply of skilled labor affects technological adoption. At the heart of the model is a choice facing firms on which production technique to employ. In our model, we choose a parsimonious approach and focus on just two choices. However, having these two choices produces a rich set of implications (richer than can be generated from more standard nested CES specifications). Our results are in many ways similar to those in the economic history literature, notably Goldin and Sokoloff (1984). We find that cities that enjoyed relative abundance of skilled labor in 1980 were those cities that adopted PCs (a skill-biased technology) most aggressively. Further, cities that adopted PCs the most aggressively were also cities that witnessed the largest increase in relative wages. In fact, the downward sloping relationship between relative wages and the supply of skilled labor that existed in 1970, 1980, and 1990 had lessened considerably by 2000. The increase in relative wages in response to PC adoption appears to be driven by gains in wages of high-skilled workers and declines of wages of low-skilled workers. 


\section{References}

Acemoglu, Daron (1998), "Why Do New Technologies Complement Skills? Directed Technical Change and Wage Inequality," Quarterly Journal of Economics, November 1998, vol 113, 1055-1089.

Acemoglu, Daron (2002), "Directed Technical Change", Review of Economic Studies, volume 69. pp. 781-810.

Altonji, Joseph and David Card (1991), "Effects of Immigration on Labor-Market Outcomes of Less-Skilled Natives," in John Abowd and Richard Freeman, eds., Immigration, Trade, and Labor p. 201-234.

Atkinson, Anthony B. and Joseph E.Stiglitz (1969), "A New View of Technological Change," Economic Journal, September, 79(3), pp.573-78.

Autor, David, Lawrence F. Katz and Melissa S. Kearney (2006), "The Polarization of the U.S. Labor Market," mimeo.

Autor, David H., Frank Levy and Richard J. Murnane (2003), "The Skill Content of Recent Technological Change: An Empirical Exploration," Quarterly Journal of Economics, 118 (4): November 2003, p. 1279-1334.

Basu, Susanto and David Weil (1998), "Appropriate Technology and Growth," Quarterly Journal of Economics, November, 113(4), pp. 1025-54.

Beaudry, Paul and David Green (1998), "What is Driving US and Canadian Wages: Exogenous Technical Change or Endogenous Choice of Technique?" (December), NBER working paper 6853 .

Beaudry, Paul and David Green (2003), "The Changing Structure of Wages in the US and Germany: What explains the differences?" American Economic Review, June , pp 573-603.

Beaudry, Paul and David Green (2005), "Changes in U.S. Wages, 1976ndash2000: Ongoing Skill Bias or Major Technological Change?" Journal of Labor Economics, vol 23 , pp. 609648.

Benhabib, Jess and Mark Spiegel (2005), "Human Capital and Technology Diffusion," forthcoming, Handbook of Economic Growth, Philippe Aghion and Steven Durlauf, eds., NorthHolland, Amsterdam. 
Black, Dan, N. Kolesnikova and L. Taylor (2004), "Understanding the Returns to Education when Wages and Prices Vary by Location," working paper.

Card, David (1995), "Using Geographic Variation in College Proximity to Estimate the Return to Schooling," in Louis N. Chiristofides, E. Kenneth Grant , and Robert Swidinsky, Eds., Aspects of Labour Market Behaviour: Essays in Honour of John Vanderkamp. Toronto: University of Toronto Press, p. 201-222.

Card, David (1999), "The Causal Effect of Education on Earnings," Handbook of Labor Economics. Volume 3A, 1999, p 1801-1863. Amsterdam, New York and Oxford: Elsevier Science, North-Holland.

Card, David and John E. DiNardo (2002), "Skill-Biased Technological Change and Rising Wage Inequality: Some Problems and Puzzles," Journal of Labor Economics, 20 (4): October 2002, pp. 733-83.

Card, David and Ethan Lewis (2005), "The Diffusion of Mexican Immigrants During the 1990s: Explanations and Impacts," NBER Working Paper no. 11552, August 2005.

Caselli, Francesco (1999), "Technological Revolutions," American Economic Review, 89:1, pp. $78-102$.

Caselli, Francesco and W. John Coleman (2006), "The World Technology Frontier," American Economic Review, forthcoming.

Comin, Diego and Bart Hobijn (2004), "Cross-Country Technology Adoption: Making the Theories Face the Facts," Journal of Monetary Economics, 2004, 51, 39-83.

Doms, Mark and Ethan Lewis (2006), "The Diffusion of Personal Computers Across the U.S., 1990-2002," Working Paper Series 2006-18, Federal Reserve Bank of San Francisco.

Gerschenkron, A. (1962), Economic Backwardness in Historical Perspective, Cambridge, Belknap Press of Harvard University Press.

Glaeser, Edward (2005), "Urban Colossus: Why is New York America's Largest City?," Harvard Institute of Economic Research Discussion Paper 2073.

Goldin, Claudia and Kenneth Sokoloff (1984), "The Relative Productivity Hypothesis of Industrialization: The American Case, 1820 to 1850," Quarterly Journal of Economics, 99 (August): 461- 488 . 
Habakkuk, H. J. American and British Technology in the Nineteenth Century. Cambridge: Cambridge University Press, 1962.

Kane, Thomas J. and Cecilia Elena Rouse (1995), "Labor Market Returns to Two- and Four-Year College," American Economic Review 85(3): June 1985, p. 600-614.

Kane, Thomas J. and Cecilia Elena Rouse (1999), "The Community College: Educating Students at the Margin Between College and Work," Journal of Economic Perspectives 13(1): Winder 1999, p. 63-84.

Katz, Lawrence F. and Kevin M. Murphy, "Changes in Relative Wages, 1963-1987: Supply and Demand Factors," Quarterly Journal of Economics 112: 1992, p 291-303.

Krueger, Alan (1993), "How Computers Have Changed the Wage Structure: Evidence from Microdata 1984-1989," Quarterly Journal of Economics 108(1): 1993, p. 33-60.

Lewis, Ethan (2003), "Local, Open Economies Within the US: How Do Industries Respond to Immigration?" Federal Reserve Bank of Philadelphia Working Paper no. 04-01, December 2003.

Lewis, Ethan (2005), "Immigration, Skill Mix, and the Choice of Technique," Federal Reserve Bank of Philadelphia Working Paper, May 2005.

Manuelli, Rodolfo and Ananth Seshadri (2004), "Frictionless Technology Diffusion: The Case of Tractors," working paper.

Moretti, Enrico (2004), "Estimating the Social Return to Higher Education: Evidence From Longitudinal and Repeated Cross-Sectional Data," Journal of Econometrics 121(1-2): JulyAugust 2004, p. 175-212.

Nervis, Allan (1962). The State Universities and Democracy. Urbana, IL: University of Illinois Press, 1962.

Welch, Finis (2000), "Growth in Women's Relative Wages and in Inequality Among Men: One Phenomenon or Two?," Papers and Proceedings of the American Economic Association, pp. 444-449. 
Table 1: PC Adoption and Education

\begin{tabular}{lcccccc}
\hline \hline & OLS & OLS & OLS & IV & IV & IV \\
\cline { 2 - 7 } & 1 & 2 & 3 & 4 & 5 & 6 \\
\hline$\left(\frac{C}{H}\right)_{2000}$ & 0.101 & - & - & 0.102 & - & - \\
$\left(\frac{C}{H}\right)_{80}$ & $(0.009)$ & & & $(0.017)$ & & \\
$\Delta\left(\frac{C}{H}\right)$ & - & 0.100 & 0.084 & - & 0.097 & 0.094 \\
& & $(0.009)$ & $(0.012)$ & & $(0.017)$ & $(0.022)$ \\
& & 0.117 & 0.088 & - & 0.174 & 0.134 \\
City Controls & - & - & yes & - & - & yes \\
& & & & & & \\
$R^{2}$ & 0.34 & 0.34 & 0.58 & & & \\
$p$-value & - & 0.65 & 0.02 & - & $2.050)$ & 0.032 \\
\hline \hline
\end{tabular}

The dependant variable is the number of PCs per worker at the city level corrected for industry composition. The variable $\frac{C}{H}$ corresponds to the log of the ratio of college equivalent workers to high school equivalent workers. The instruments used are measures of local college availability and attendance patterns as of 1971. The reported p-value is associated to the test of equality of coefficients on $\left(\frac{C}{H}\right)_{80}$ and $\Delta\left(\frac{C}{H}\right)$, where the latter is the change over the period 1980-2000. The city level controls correspond the the log of the labor force, the unemployment rate, the fraction of city population which is female, African-American, and U.S. citizens. The regressions were run on 230 observations and weighted by the square root of the size of the labor force. 
Table 2: PC Adoption and Initial Returns to Skill

\begin{tabular}{|c|c|c|c|c|}
\hline & OLS & OLS & OLS & IV \\
\hline & 1 & 2 & 3 & 4 \\
\hline \multirow{2}{*}{$\left(\frac{w^{C}}{w^{H}}\right)_{80}$} & -0.231 & -0.250 & -0.195 & -0.201 \\
\hline & $(0.054)$ & $(0.057)$ & $(0.059)$ & $(0.092)$ \\
\hline \multirow[t]{2}{*}{$\Delta\left(\frac{C}{H}\right)$} & - & 0.028 & 0.053 & 0.066 \\
\hline & & $(0.028)$ & $(0.032)$ & $(0.138)$ \\
\hline City Controls & yes & yes & yes & yes \\
\hline Ind. Shares & - & - & yes & yes \\
\hline$R^{2}$ & 0.36 & 0.37 & 0.45 & \\
\hline
\end{tabular}

The dependant variable is the number of PCs per worker at the city level corrected for industry composition. The variable $\left(\frac{w^{C}}{w^{H}}\right)_{80}$ corresponds to the relative wage of college to high-school workers. The instruments used are measures of local college availability and attendance patterns as of 1971. The variable $\Delta\left(\frac{C}{H}\right)$ corresponds to the 1980-2000 change in the skill level of the city's workforce. The city level controls correspond the the log of the labor force, the unemployment rate, the fraction of city population which is female, African-American, and U.S. citizens. The industry controls include the share of the workforce in 12 major industry groups. The regressions were run on 230 observations and weighted by the square root of the size of the labor force.

Table 3: Changes in Returns and PC Adoption

\begin{tabular}{|c|c|c|c|c|c|c|}
\hline & $\overline{\mathrm{OOLS}}$ & $\overline{\text { OLS }}$ & $\overline{\text { OLS }}$ & IV & IV & $\overline{\mathrm{IV}}$ \\
\hline & 1 & 2 & 3 & 4 & 5 & 6 \\
\hline \multirow{2}{*}{$\left(\frac{P C}{L}\right)_{2000}$} & 0.107 & 0.042 & 0.049 & 1.073 & 1.158 & 0.896 \\
\hline & $(0.074)$ & $(0.077)$ & $(0.076)$ & $(0.259)$ & $(0.391)$ & $(0.293)$ \\
\hline \multirow[t]{2}{*}{$\Delta\left(\frac{C}{H}\right)$} & - & - & -0.061 & - & $\begin{array}{lll}- & \\
\end{array}$ & -0.081 \\
\hline & & & $(0.035)$ & & & $(0.045)$ \\
\hline City Controls & yes & yes & yes & yes & yes & yes \\
\hline Ind. Shares & - & yes & yes & - & yes & yes \\
\hline$R^{2}$ & 0.26 & 0.35 & 0.36 & - & - & - \\
\hline
\end{tabular}

The dependent variable is the change in the log ratio of college to high school wages, where wages are adjusted for experience and gender. The instrument used for PCs is the ratio of college to high school equivalent workers in 1980. See the notes in Table 1 and Table 2 about sample size, controls, and weighting. 
Table 4: Returns to Education and PCs in 2000

\begin{tabular}{|c|c|c|c|c|c|c|}
\hline & OLS & OLS & OLS & IV & IV & IV \\
\hline & 1 & 2 & 3 & 4 & 5 & 6 \\
\hline \multirow{2}{*}{$\left(\frac{P C}{L}\right)_{2000}$} & -0.184 & -0.234 & -0.099 & -0.526 & -1.467 & -3.398 \\
\hline & $(0.076)$ & $(0.078)$ & $(0.079)$ & $(0.217)$ & $(0.357)$ & ( 3.433$)$ \\
\hline \multirow{2}{*}{$\left(\frac{C}{H}\right)_{2000}$} & - & - & -0.118 & . & - & 0.229 \\
\hline & & & $(0.024)$ & - & & $(0.367)$ \\
\hline City Controls & yes & yes & yes & yes & yes & yes \\
\hline Ind. Shares & - & yes & yes & - & yes & yes \\
\hline$R^{2}$ & 0.39 & 0.46 & 0.52 & - & - & - \\
\hline
\end{tabular}

The dependant variable is the log ratio of college to high-school wages, where the wages are adjusted to control for experience and gender. The PC-measure controls for industry composition. See the notes in Table 1 and Table 2 about sample size, controls, and weighting.

Table 5: Changes in Relative Wages and Skill: Reduced Form Relationships

\begin{tabular}{|c|c|c|c|c|c|c|}
\hline & 1 & 2 & 3 & 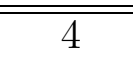 & 5 & 6 \\
\hline \multirow{2}{*}{$\left(\frac{C}{H}\right)_{1980}$} & 0.054 & 0.063 & 0.086 & - & - & - \\
\hline & $(0.011)$ & $(0.014)$ & $(0.022)$ & & & \\
\hline \multirow{2}{*}{$\Delta\left(\frac{C}{H}\right)$} & -0.083 & -0.040 & 0.001 & -0.079 & -0.047 & 0.013 \\
\hline & $(0.027)$ & $(0.034)$ & $(0.037)$ & $(0.027)$ & $(0.029)$ & $(0.032)$ \\
\hline \multirow{2}{*}{$\left(\frac{w^{C}}{w^{H}}\right)_{1980}$} & - & - & - & -0.320 & -0.442 & -0.474 \\
\hline & & & & $(0.062)$ & $(0.057)$ & $(0.059)$ \\
\hline City Controls & - & yes & yes & - & yes & yes \\
\hline Ind. Shares & - & - & yes & - & - & yes \\
\hline$R^{2}$ & 0.16 & 0.35 & 0.41 & 0.17 & 0.44 & 0.51 \\
\hline
\end{tabular}

The dependent variable is the change in log ratio of college to high school wages, where wages are adjusted for experience and gender. See the notes in Table 1 and Table 2 about sample size, controls, and weighting. 
Table 6: Relative Wages and Supply of Skills (all OLS)

\begin{tabular}{|c|c|c|c|c|c|c|}
\hline & $18(2000)$ & $2(1990)$ & $3(1980)$ & 4 & $5(1990)$ & 6 6(1980) \\
\hline \multirow[t]{2}{*}{$\left(\frac{C}{H}\right)_{2000}$} & -0.001 & $\begin{array}{ll}- & \text { - }\end{array}$ & - & -0.028 & $\begin{array}{lll}- & \\
\end{array}$ & - \\
\hline & $(0.014)$ & & & $(0.015)$ & & \\
\hline \multirow{2}{*}{$\left(\frac{C}{H}\right)_{1990}$} & - & -0.055 & $\begin{array}{l}- \\
-\end{array}$ & $\begin{array}{ll}- & \text { - }\end{array}$ & -0.055 & - \\
\hline & & $(0.012)$ & & & $(0.014)$ & \\
\hline \multirow[t]{2}{*}{$\left(\frac{C}{H}\right)_{1980}$} & - & - & -0.066 & - & - & -0.106 \\
\hline & & & $(0.011)$ & & & $(0.012)$ \\
\hline C. Cont. & $\begin{array}{ll}- & \text { r }\end{array}$ & $\begin{array}{lll}- & \\
-1\end{array}$ & $\begin{array}{lll}- & \\
-1\end{array}$ & yes & yes & yes \\
\hline$R^{2}$ & 0.00 & 0.08 & 0.13 & 0.38 & 0.31 & 0.38 \\
\hline
\end{tabular}

The dependent variable is log ratio of college to high school wages, where wages are adjusted for experience and gender. The variable $\frac{C}{H}$ corresponds to the $\log$ of the ratio of college equivalent workers to high school equivalent workers. See the notes in Table 1 and Table 2 about sample size, controls, and weighting.

Table 7: Changes in Wages and PCs: College and High School Educated Workers

\begin{tabular}{lcccccc}
\hline \hline & 1 & 2 & 3 & 4 & 5 & 6 \\
\hline & HS & Coll & HS & Coll & HS & Coll \\
\hline \multirow{2}{*}{$\left(\frac{P C}{L}\right)_{2000}$} & OLS & OLS & IV & IV & IV & IV \\
\multirow{2}{*}{$\Delta\left(\frac{C}{H}\right)$} & -0.117 & -0.010 & -0.607 & 0.652 & -0.470 & .465 \\
\multirow{2}{*}{ City Controls } & $(0.080)$ & $(0.094)$ & $(0.222)$ & $(0.266)$ & $(0.192)$ & $(0.228)$ \\
& - & - & - & - & 0.043 & -0.055 \\
$R^{2}$ & yes & yes & yes & yes & yes & yes \\
\hline \hline
\end{tabular}

The dependant variable is either the percentage increase in the wage of high school educated workers or the percentage increase in the wage of college educated workers. For the columns indicated by IV, the variable $\frac{P C}{L}$ is instrumented by the ratio of college to high school educated workers in 1980 and the return to college in 1980. See the notes in Table 1 and Table 2 about sample size, controls, and weighting. 


\section{Figure 4: PCs per Employee by City in 1990 and 2000: Difference from the San Francisco Bay Area}

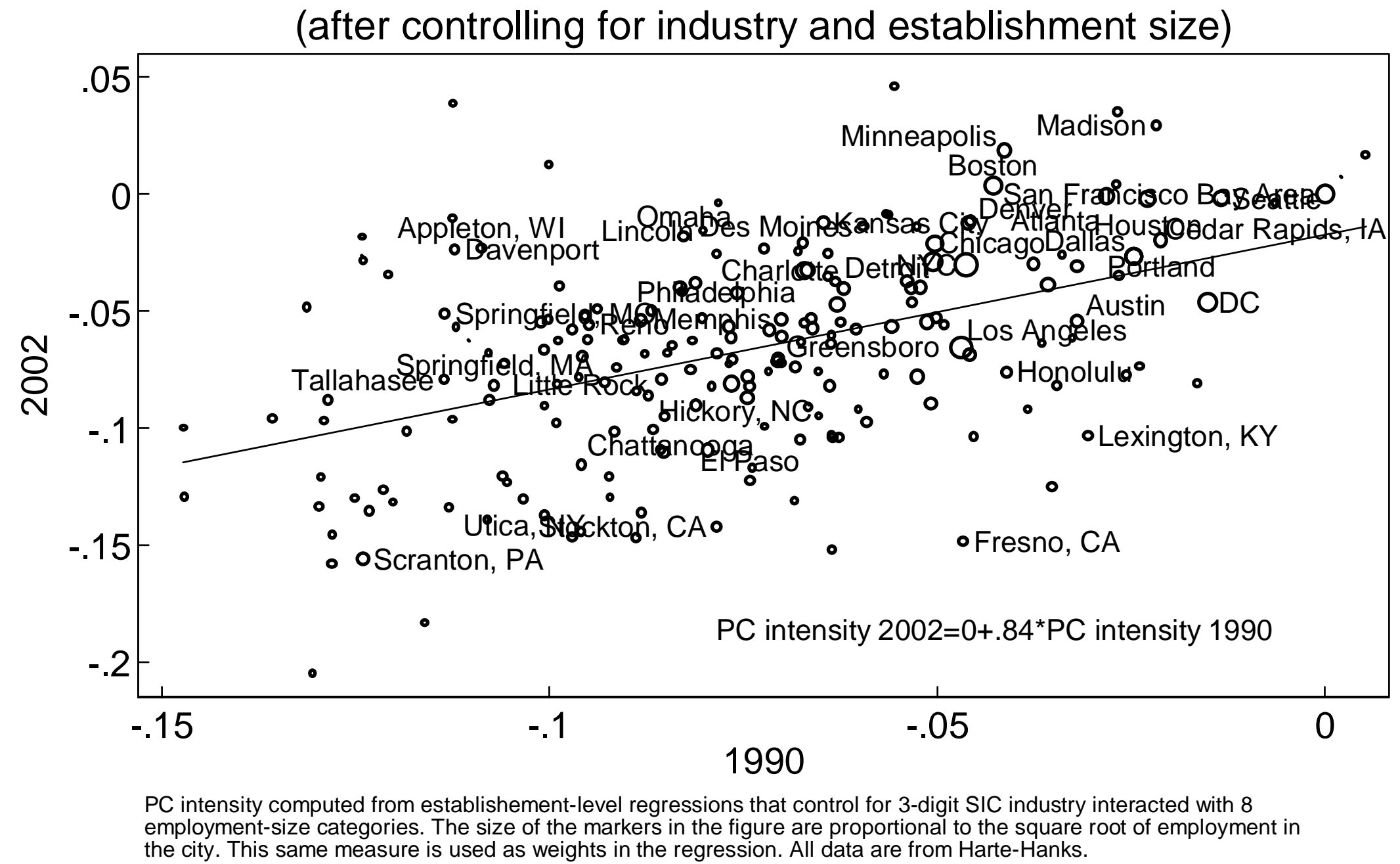




\section{Figure 5: Log of College to High School Equivalents 2000 and 1980}

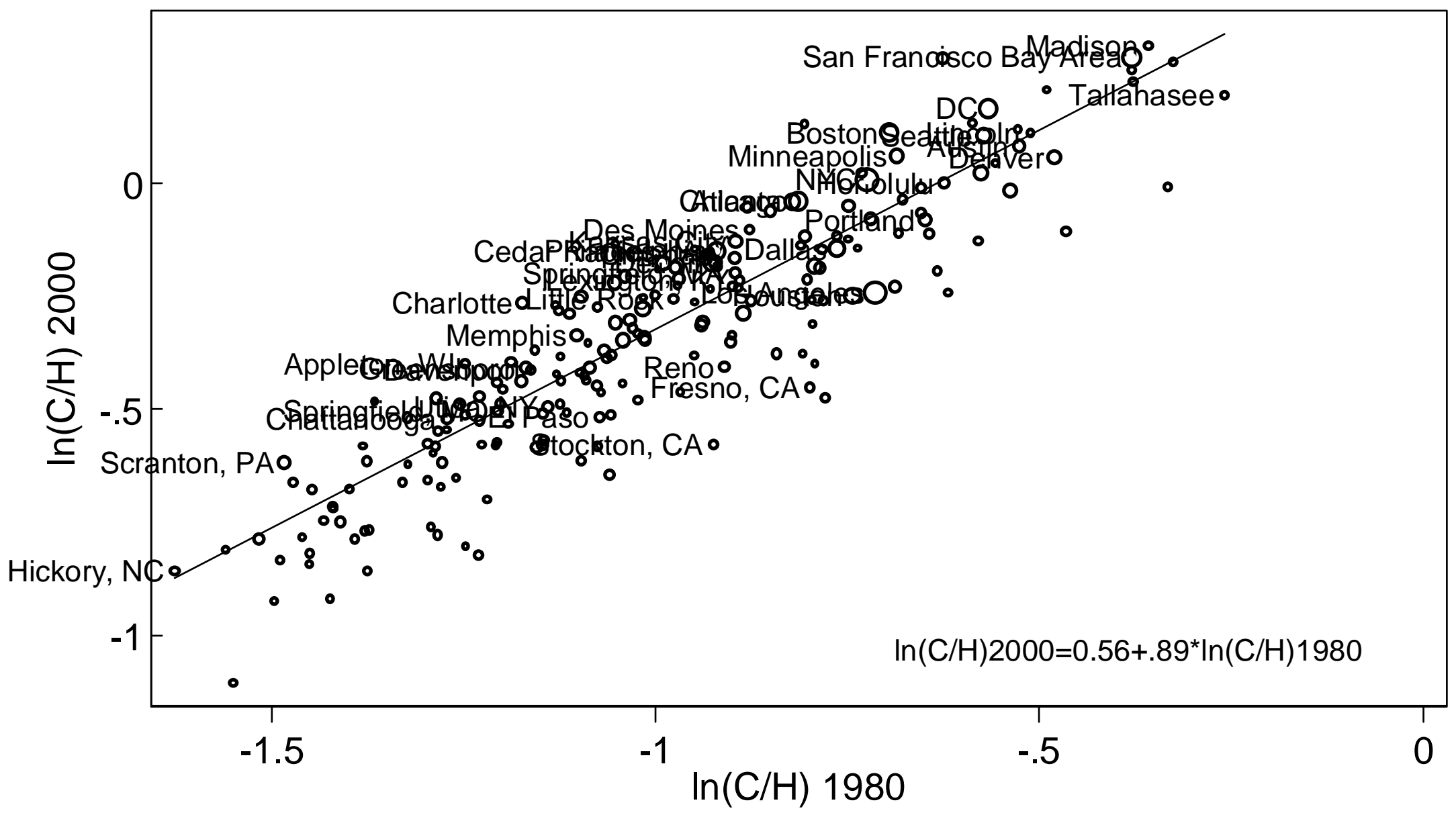

The size of the markers in the figure are proportional to the square root of employment in the city. This same measure is used as weights in the regression. College equivalents is defined as those with a college degree or more plus $1 / 2$ of those with some college. All data come from the PUMS 


\section{Figure 6: PC Intensity and Skills in 2000}

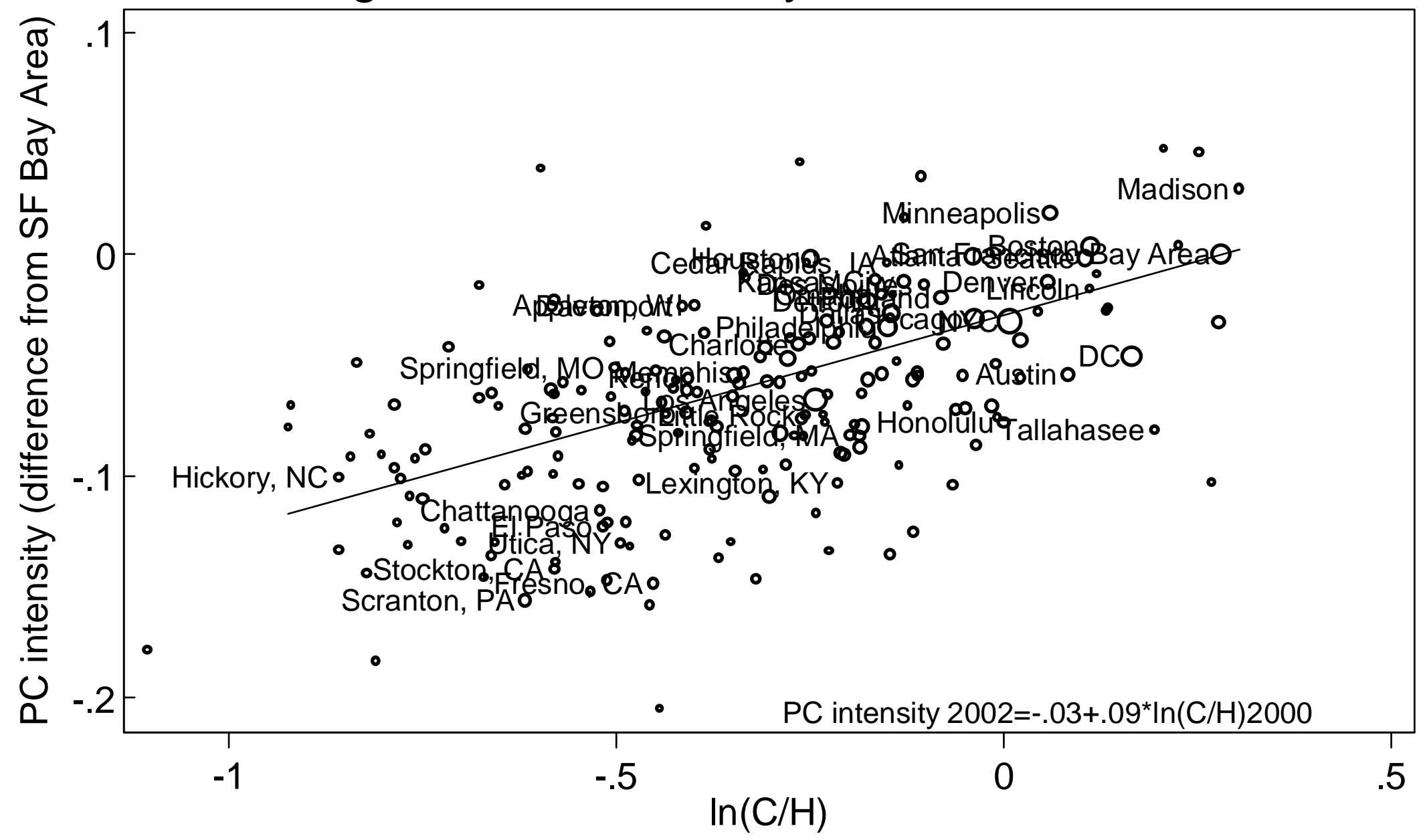

PC intensity computed from establishement-level regressions that control for 3-digit SIC industry interacted with 8 employment-size categories. $\mathrm{C} / \mathrm{H}$ is the ratio of college equivalent workers to high school equivalent workers. The size of the markers in the figure are proportional to the square root of employment in the city. This same measure is used as weights in the regression. 
Figure 7a: Initial Skill and Changes in the Relative Wages, 1980-2000

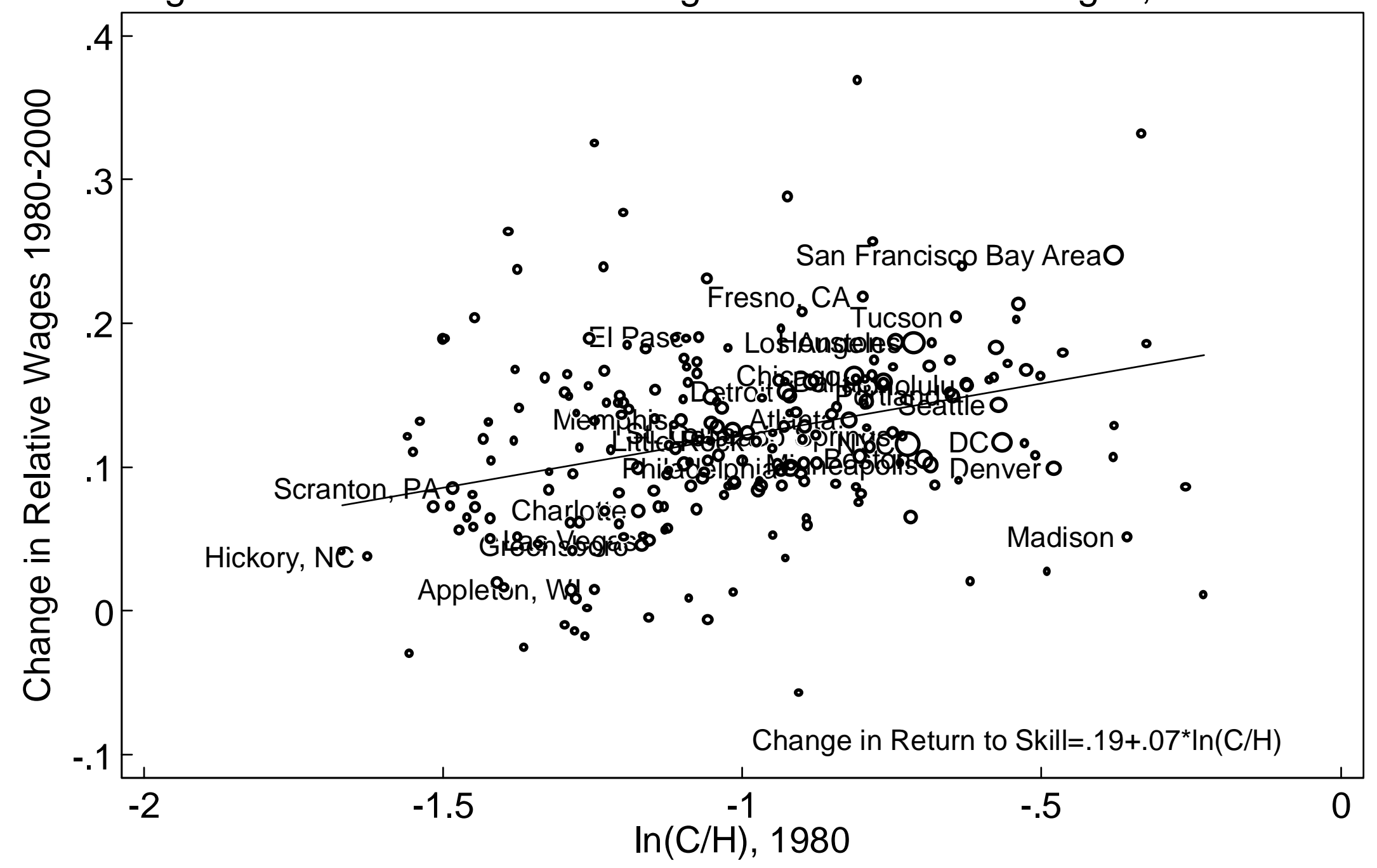

$\mathrm{C} / \mathrm{H}$ is the ratio of college equivalent workers to high school equivalent workers. The size of the markers in the figure are proportional to the square root of employment in the city. This same measure is used as weights in the regression. 
Figure 7b: Initial Skill and Changes in the Relative Wages, 1990-2000

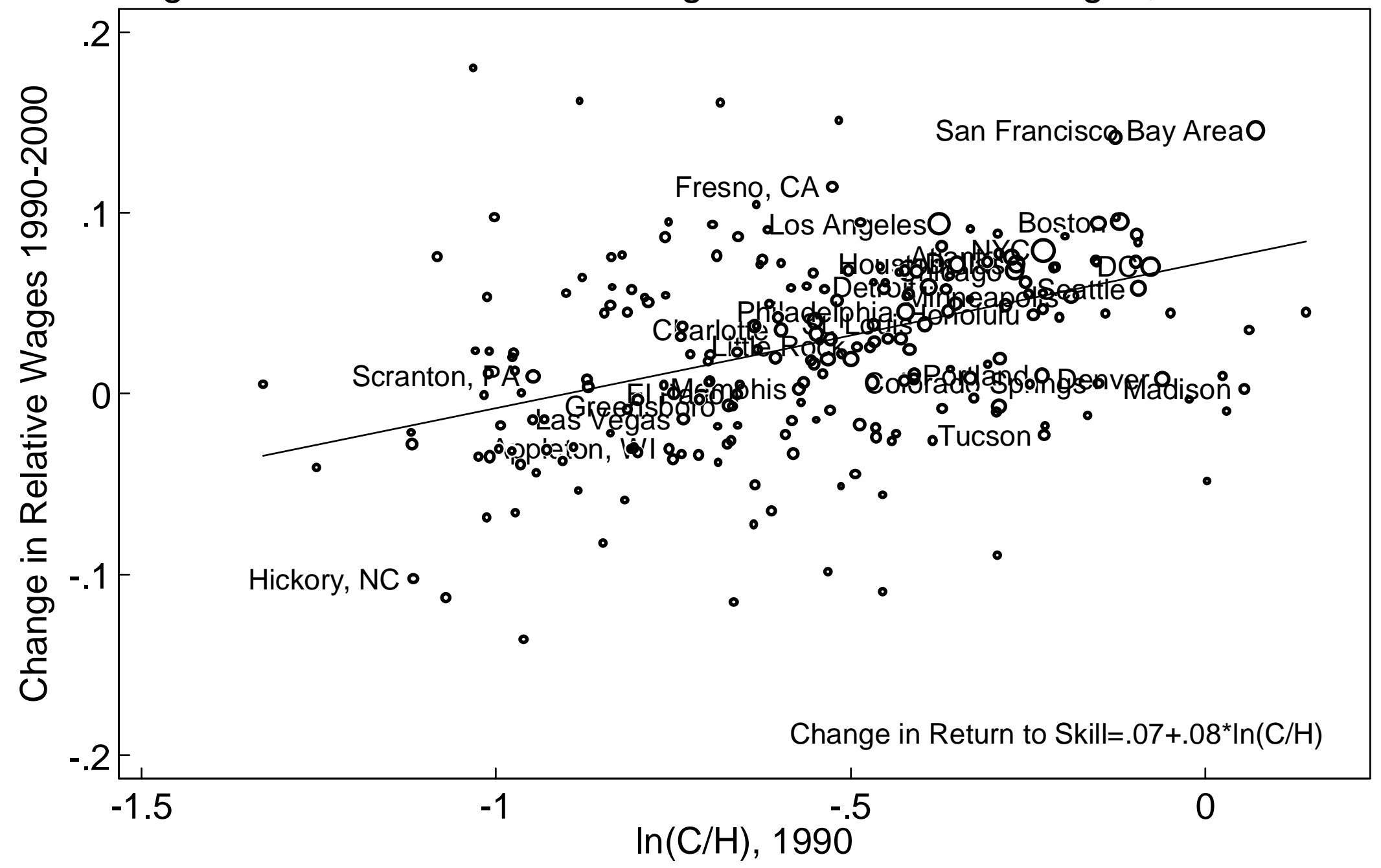

$\mathrm{C} / \mathrm{H}$ is the ratio of college equivalent workers to high school equivalent workers. The size of the markers in the figure are proportional to the square root of employment in the city. This same measure is used as weights in the regression. 
Figure 7c: Initial Skill and Changes in the Relative Wages, 1980-1990

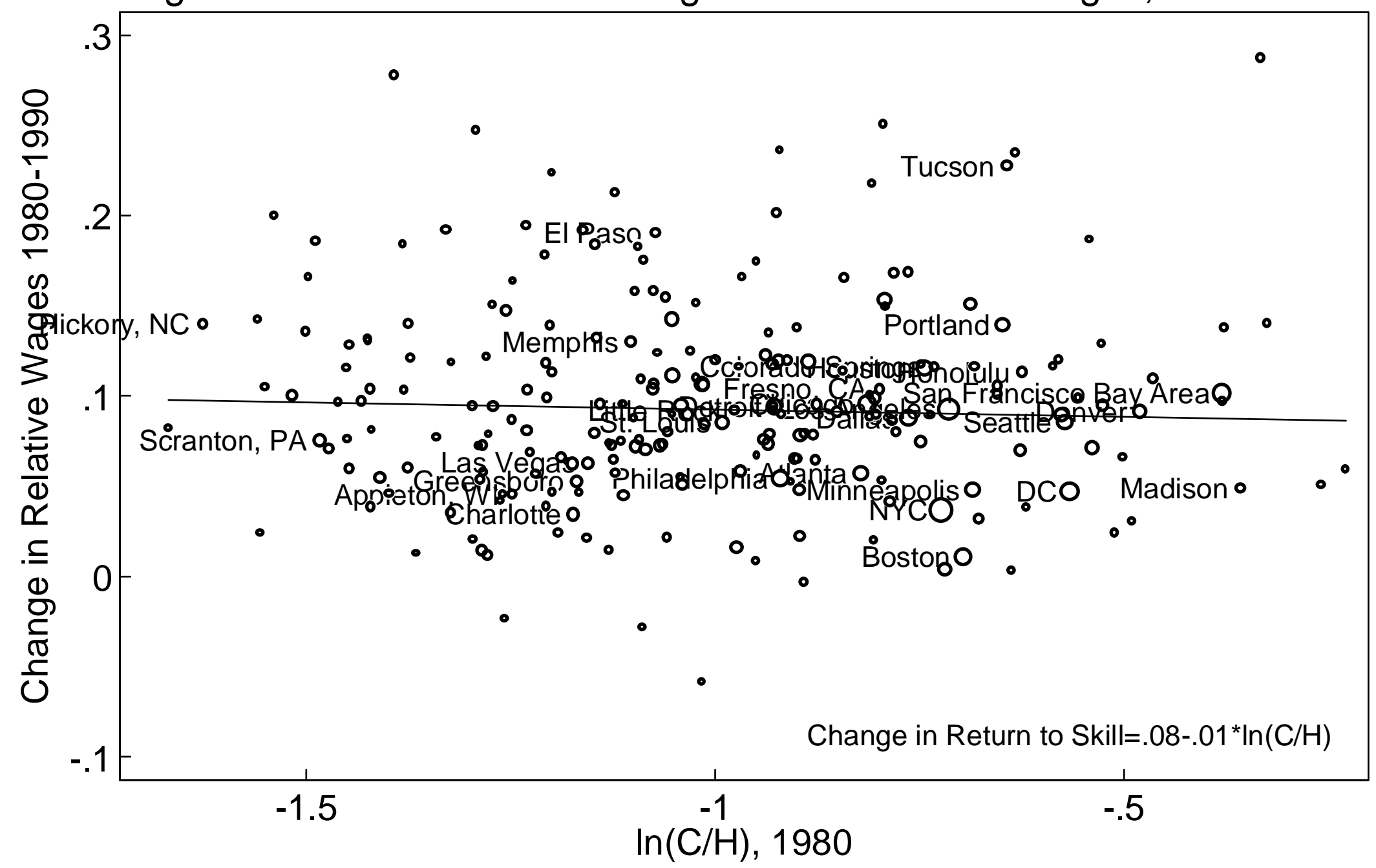

$\mathrm{C} / \mathrm{H}$ is the ratio of college equivalent workers to high school equivalent workers. The size of the markers in the figure are proportional to the square root of employment in the city. This same measure is used as weights in the regression. 


\section{Figure 8a: Relative Wages and Skill Mix in 1970}

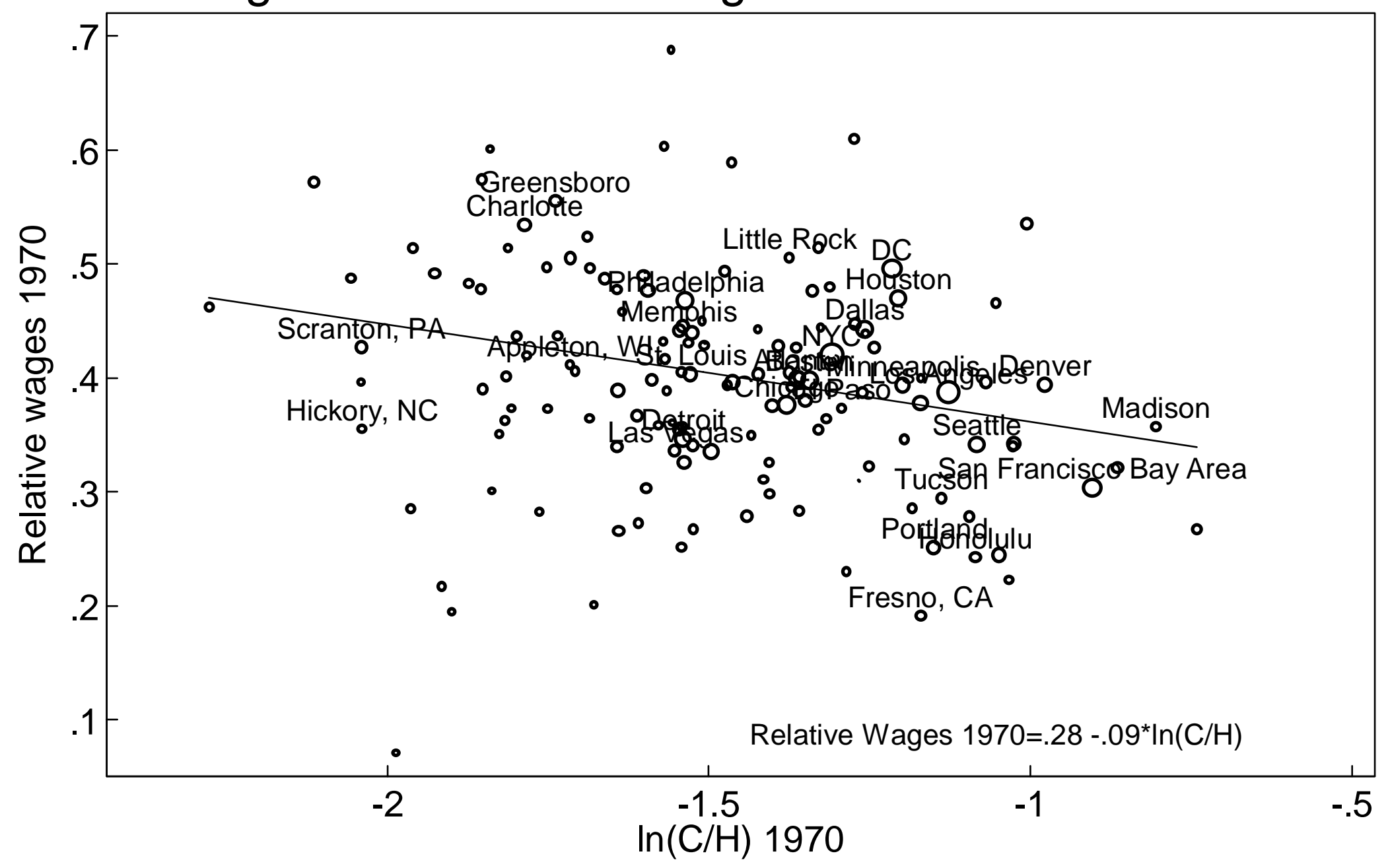

$\mathrm{C} / \mathrm{H}$ is the ratio of college equivalent workers to high school equivalent workers. The size of the markers in the figure are proportional to the square root of employment in the city. This same measure is used as weights in the regression. 


\section{Figure 8b: Relative Wages and Skill Mix in 1980}

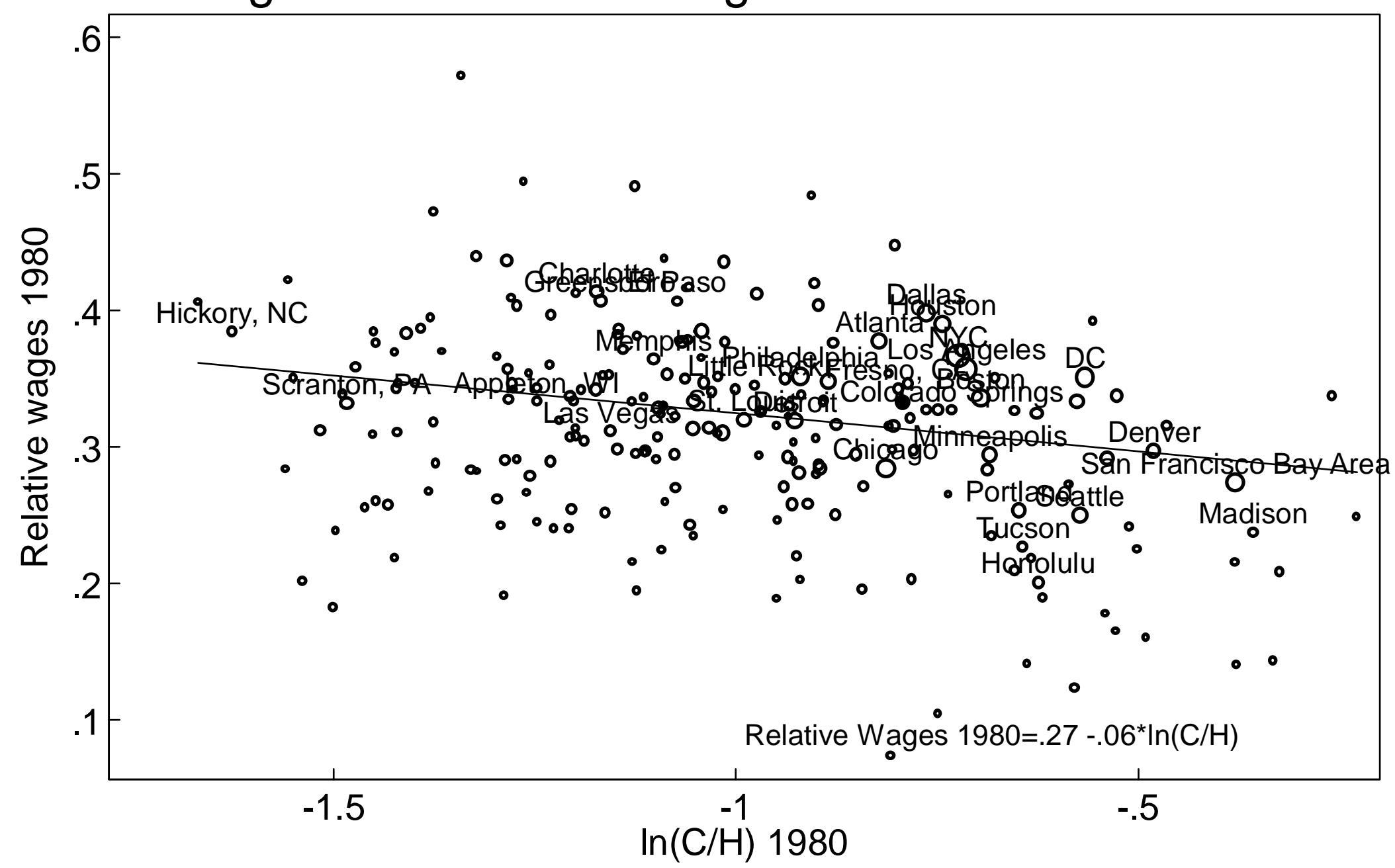

$\mathrm{C} / \mathrm{H}$ is the ratio of college equivalent workers to high school equivalent workers. The size of the markers in the figure are proportional to the square root of employment in the city. This same measure is used as weights in the regression. 
Figure 8c: Relative Wages and Skill Mix in 1990

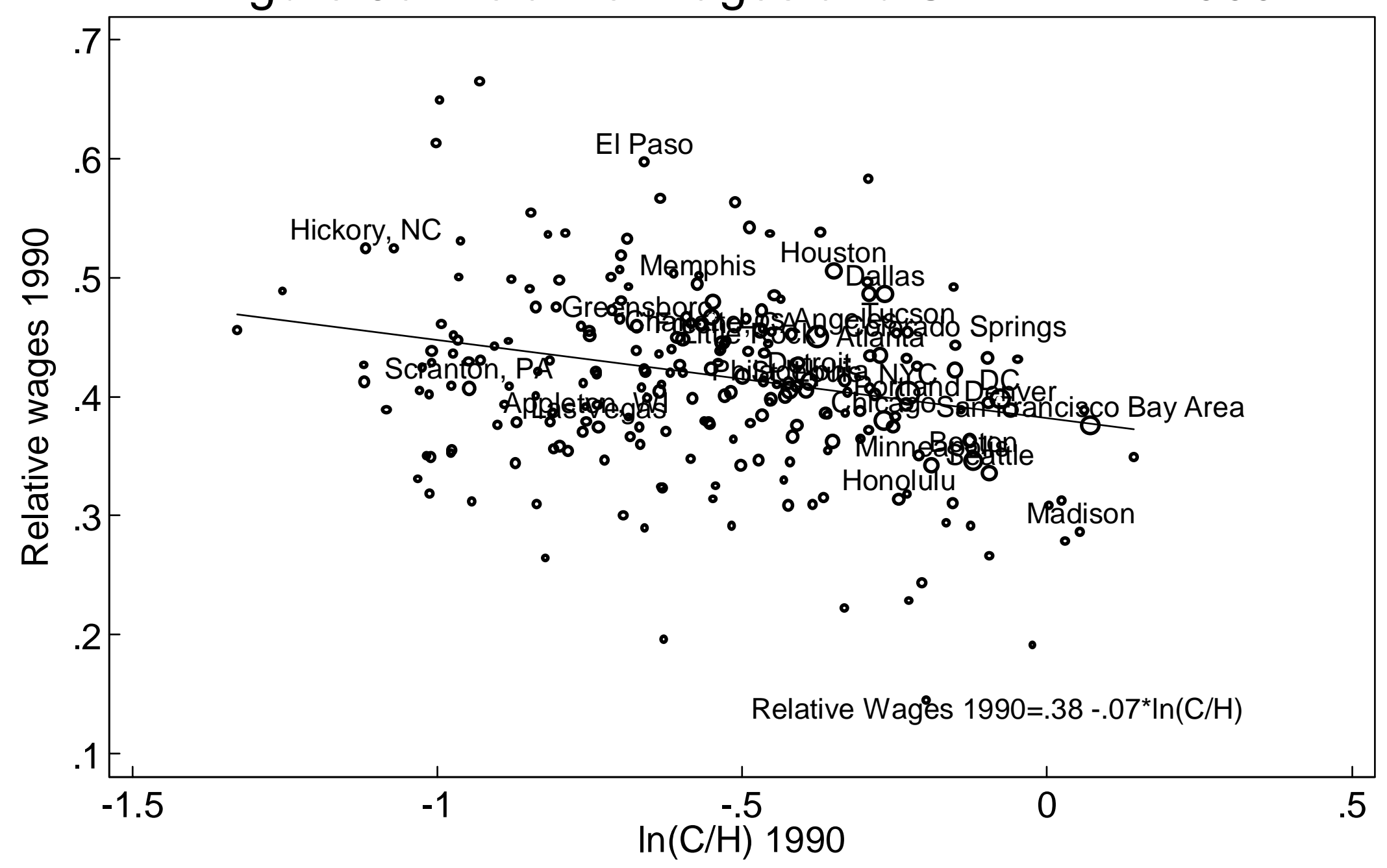

$\mathrm{C} / \mathrm{H}$ is the ratio of college equivalent workers to high school equivalent workers. The size of the markers in the figure are proportional to the square root of employment in the city. This same measure is used as weights in the regression. 
Figure 8d: Relative Wages and Skill Mix in 2000

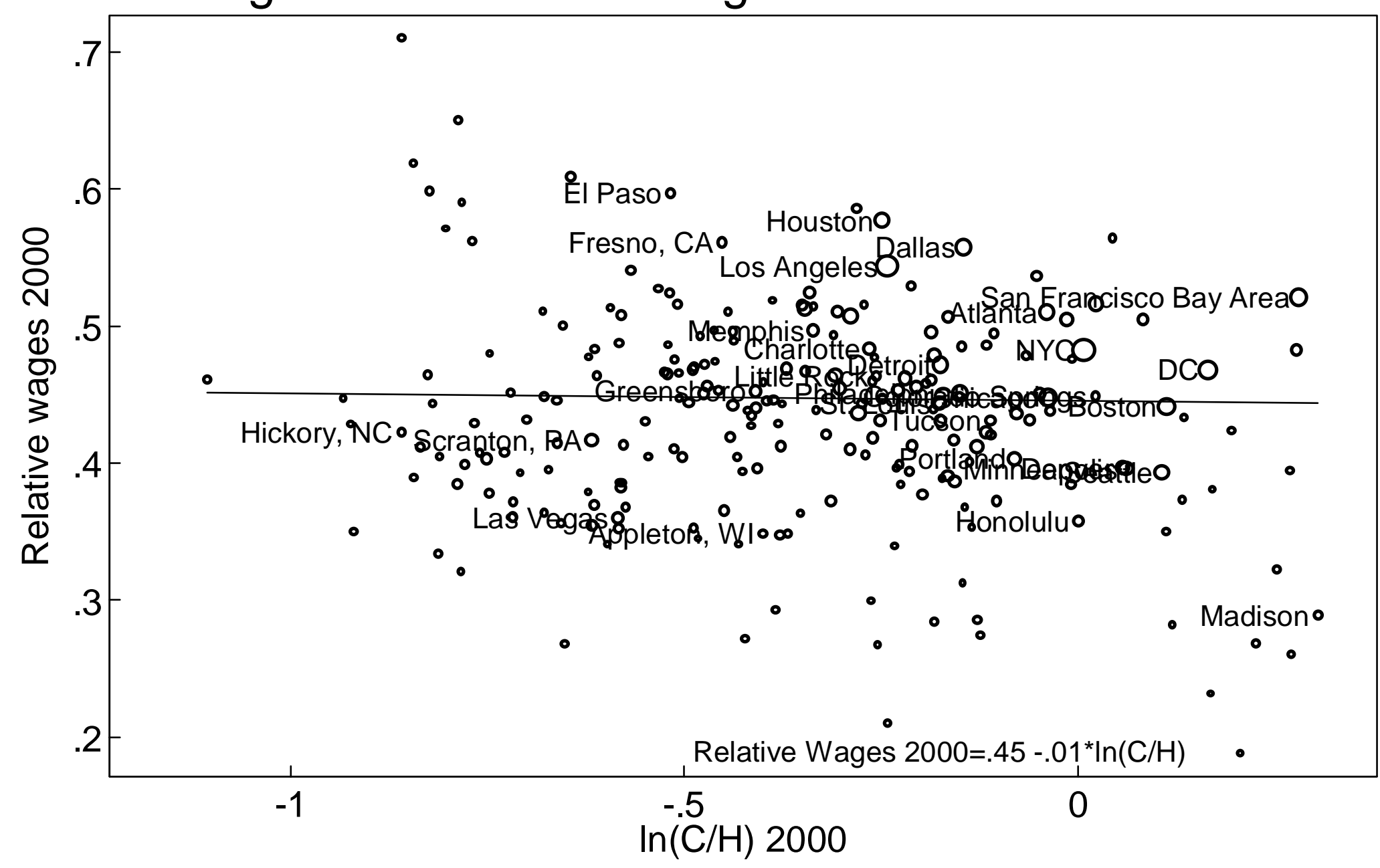

$\mathrm{C} / \mathrm{H}$ is the ratio of college equivalent workers to high school equivalent workers. The size of the markers in the figure are proportional to the square root of employment in the city. This same measure is used as weights in the regression. 


\section{Figure 9. College Share and Changes in Industry Mix}

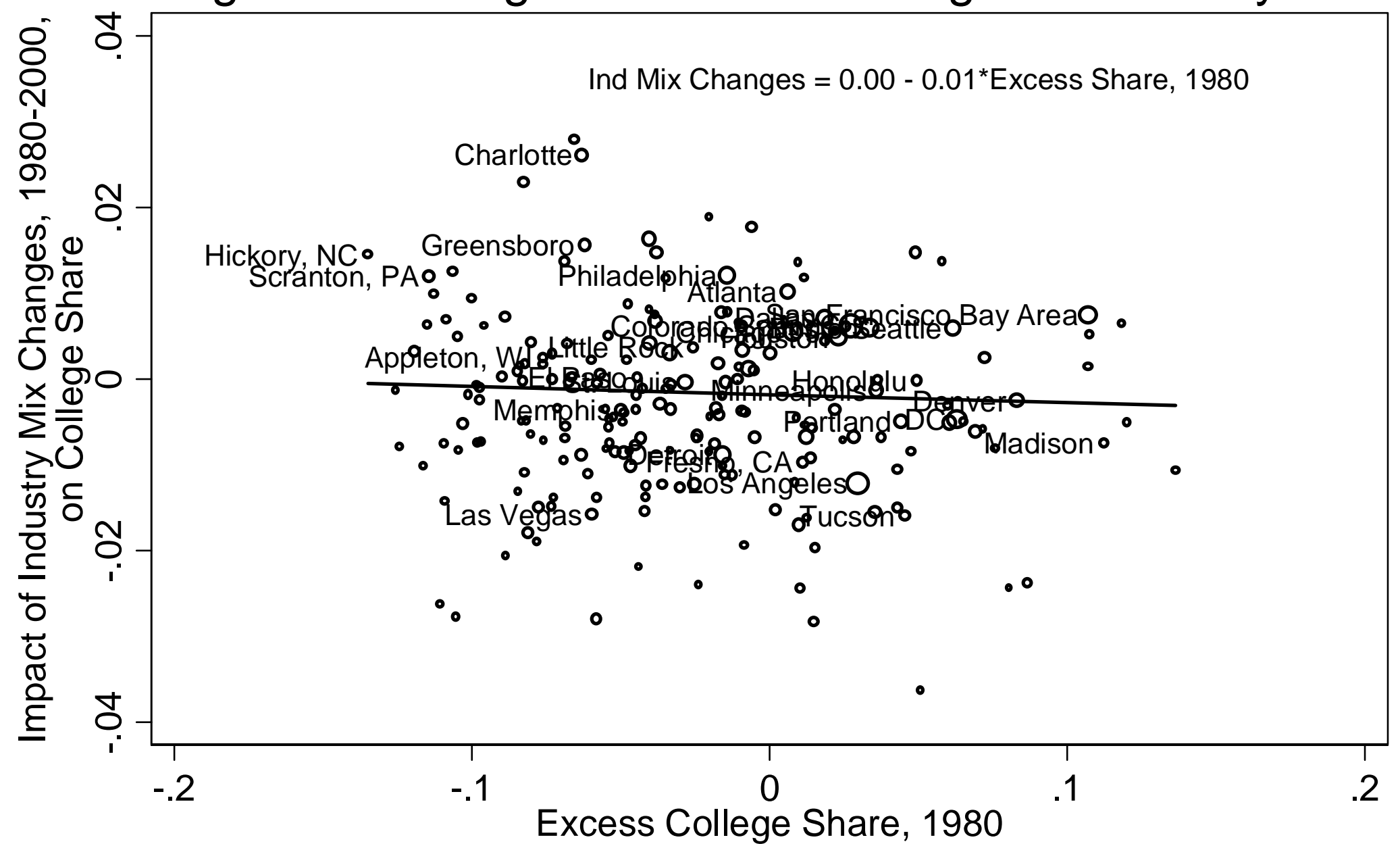

Excess college share is the college equivalent share in the city minus the college equivalent share in all cities. College equivalent share is the share of workers with a college degree plus $1 / 2$ of those with some college education but no degree. The y-axis shows the impact of industry mix changes on college share; how this was calculated is described in the text. All calculations come from PUMS for 1980 and 2000. 